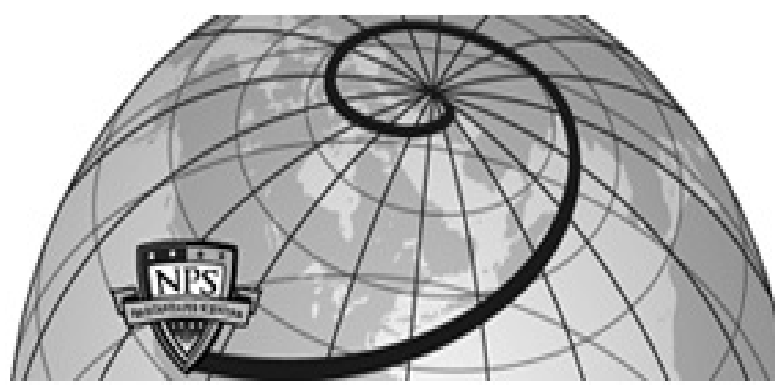

Calhoun: The NPS Institutional Archive DSpace Repository

Observations of a Nondeveloping Tropical Disturbance in the Western North Pacific during TCS-08 (2008)

Penny, Andrew B.; Harr, Patrick A.; Bell, Michael M.

Monthly Weather Review, Volume 143, pp. 2459-2484, July 2015

http://hdl.handle.net/10945/45774

This publication is a work of the U.S. Government as defined in Title 17, United States Code, Section 101. Copyright protection is not available for this work in the United States.

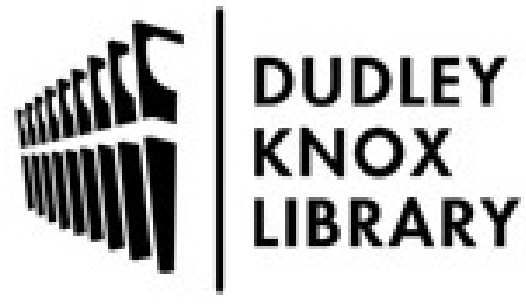

http://www.nps.edu/library
Calhoun is the Naval Postgraduate School's public access digital repository for research materials and institutional publications created by the NPS community. Calhoun is named for Professor of Mathematics Guy K. Calhoun, NPS's first appointed -- and published -- scholarly author.

Dudley Knox Library / Naval Postgraduate School 411 Dyer Road / 1 University Circle Monterey, California USA 93943 


\title{
Observations of a Nondeveloping Tropical Disturbance in the Western North Pacific during TCS-08 (2008)
}

\author{
Andrew B. Penny And PATrick A. Harr \\ Naval Postgraduate School, Monterey, California \\ MiCHAEL M. BELL \\ University of Hawai'i at Mānoa, Honolulu, Hawaii
}

(Manuscript received 21 May 2014, in final form 6 January 2015)

\begin{abstract}
Large uncertainty still remains in determining whether a tropical cloud cluster will develop into a tropical cyclone. During The Observing System Research and Predictability Experiment (THORPEX) Pacific Asian Regional Campaign (T-PARC)/Tropical Cyclone Structure-2008 (TCS-08) field experiment, over 50 tropical cloud clusters were monitored for development, but only 4 developed into a tropical cyclone. One nondeveloping tropical disturbance (TCS025) was closely observed for potential formation during five aircraft research missions, which provided an unprecedented set of observations pertaining to the large-scale and convective environments of a nondeveloping system.

The TCS025 disturbance was comprised of episodic convection that occurred in relation to the diurnal cycle along the eastern extent of a broad low-level trough. The upper-level environment was dominated by two cyclonic cells in the tropical upper-tropospheric trough (TUTT) north of the low-level trough in which the TCS025 circulation was embedded. An in-depth examination of in situ observations revealed that the nondeveloping circulation was asymmetric and vertically misaligned, which led to larger system-relative flow on the mesoscale. Persistent environmental vertical wind shear and horizontal shearing deformation near the circulation kept the system from becoming better organized and appears to have allowed low equivalent potential temperature $\left(\theta_{e}\right)$ air originating from one of the TUTT cells to the north (upshear) to impact the thermodynamic environment of TCS025. This in turn weakened subsequent convection that might otherwise have improved alignment and contributed to the transition of TCSO25 to a tropical cyclone.
\end{abstract}

\section{Introduction}

Only a small fraction of all tropical disturbances that occur over tropical ocean basins develop into tropical cyclones (Gray 1982; Lee 1989; Simpson et al. 1997; Fu et al. 2012). Gray (1998, 37-38) commented that to adequately understand the process of tropical cyclogenesis we must "thoroughly document the physical differences between those systems which develop into tropical cyclones from those prominent tropical disturbances which have a favorable climatological and synoptic environment, look very much like they will develop but still do not."

Radiosonde composites of developing and nondeveloping tropical systems in the western North Pacific

Corresponding author address: Andrew B. Penny, Department of Meteorology, Naval Postgraduate School, 589 Dyer Rd., Root Hall, Room 254, Monterey, CA 93943-5114.

E-mail: abpenny@nps.edu and North Atlantic were constructed by McBride (1981) and McBride and Zehr (1981). The most notable characteristics differentiating the developing composites were (i) larger low-level relative vorticity, (ii) areas of nearly zero vertical wind shear centered on the developing systems, and (iii) a vertical wind shear structure in the surrounding environment indicative of an anticyclone aloft.

Analyses of more recent observations have led to several hypotheses regarding tropical storm formation. Raymond and Sessions (2007), Raymond et al. (2011), and Gjorgjievska and Raymond (2014) have suggested that a vertical mass flux maximum in the low levels, or a "bottom-heavy" mass flux profile, is most conducive for storm formation through the horizontal flux convergence of low-level vorticity (i.e., low-level spinup), and that a stabilization of the thermodynamic profile results in lowering the level of maximum vertical mass flux. 
Davis and Ahijevych $(2012,2013)$ found evidence of this stabilization from dropwindsonde data collected during the Pre-Depression Investigation of Cloudsystems in the Tropics (PREDICT) field experiment (Montgomery et al. 2012), as low-level cooling occurred prior to storm formation for two developing systems. However, a similar study of PREDICT cases by Smith and Montgomery (2012) concluded that there was slight warming in the lower troposphere for both developing disturbances and the nondeveloping disturbance (Gaston) examined. Davis and Ahijevych (2012) suggested the low-level warming found by Smith and Montgomery (2012) could be due to the inclusion of dropwindsondes outside of the central convective region, which would act to obscure a lower-tropospheric cooling signal if present. Raymond and López Carrillo (2011) and Lussier et al. (2014) utilized high-resolution airborne Doppler radar and aircraft data to note that the level of maximum vertical mass flux lowered during the development of Typhoon (TY) Nuri (2008), however the low-level mass flux calculated by Lussier et al. (2014) was stronger than that found by Raymond and López Carrillo (2011) earlier in the genesis process.

Differences in dropwindsonde moisture profiles for developing and nondeveloping systems during PREDICT were also examined. Komaromi (2013) found that nondeveloping systems were on average 10\%-20\% drier between 500 and $700 \mathrm{hPa}$ than the mean, but were actually moister in the low levels. Komaromi (2013) suggested that midlevel dry air may have a larger negative impact on storm formation (through convective entrainment) compared to dry air in the low levels. Davis and Ahijevych (2012) found that the midtropospheric moist static energy increased over time for the developing systems analyzed, while the nondeveloping system (Gaston) exhibited a decrease in moist static energy and an increase in downdraft convective available potential energy (DCAPE). Smith and Montgomery (2012) also found that the mid- and upper troposphere became progressively drier for Gaston and suggested that the midlevel dry air observed in nondeveloping systems might act to dilute updraft intensity and limit the amplification of lower-tropospheric vorticity by vortex stretching (Bell and Montgomery 2010).

In addition to the thermodynamic and moisture considerations, the mesoscale structure and vertical alignment of developing-nondeveloping circulations have also been an area of recent focus. Davis and Ahijevych (2012) concluded that the vertical misalignment of the vortex led to stronger system-relative flow for Gaston, which made the incipient disturbance more susceptible to dry air in the surrounding environment. Davis and Ahijevych (2012) suggested that continual deep convection might lead to vortex realignment by initiating new lower-tropospheric circulations below the midtropospheric circulation.

Raymond and López Carrillo (2011) found that vertically overlapping closed circulations in the boundary layer and at 5-km elevation provided a deep region of protection from negative environmental influences during the formation of TY Nuri. Montgomery et al. (2010) suggested that despite the detrimental influences of strong vertical wind shear and dry air during the early stages of TY Nuri, the presence of a quasi-closed circulation in the system-relative frame (wave pouch) characterized by recirculating flow (Dunkerton et al. 2009) protected the incipient vortex until it could reach a more favorable environment. They further hypothesized that an increase in the depth of the wave pouch is favorable for storm formation and may have occurred prior to the formation of TY Nuri. Lussier et al. (2014) provided further evidence for the importance of the wave pouch and its improved vertical alignment over time that supported the mesoscale spinup at low and midlevels in TY Nuri. Similarly, Tory et al. (2013) analyzed several cases of tropical storm formation in the northern Australian region and found that the vertical alignment of regions of recirculating, low-deformation flow in the low and midlevels was important for further development.

During the combined The Observing System Research and Predictability Experiment (THORPEX) Pacific Asian Regional Campaign (T-PARC)/Tropical Cyclone Structure-2008 (TCS-08) field program in the western North Pacific (Elsberry and Harr 2008), approximately 50 tropical cloud clusters were identified in satellite imagery as potential precursors to tropical cyclone formation. Of these, only 12 reached or exceeded tropical depression (TD) status. One of these nondeveloping systems, referred to as TCS025, was closely monitored from 24 August to 3 September 2008 since global models consistently predicted intensification (not shown). However, development failed to occur. In this study, observations collected during TCS025 (Fig. 1) are examined within the context of recent tropical cyclogenesis theories to evaluate thermodynamic and dynamic factors associated with its nondevelopment. Since there often exists a great amount of uncertainty with respect to the likelihood of formation (as was the case of TCS025), an in-depth analysis of a "null case" is arguably just as important as documenting storm formation.

Based on an observational analysis, it will be shown that TCS025 was under the influence of northerly vertical wind shear and within an environment characterized by large horizontal shearing deformation. The circulation structure of TCS025 was vertically 


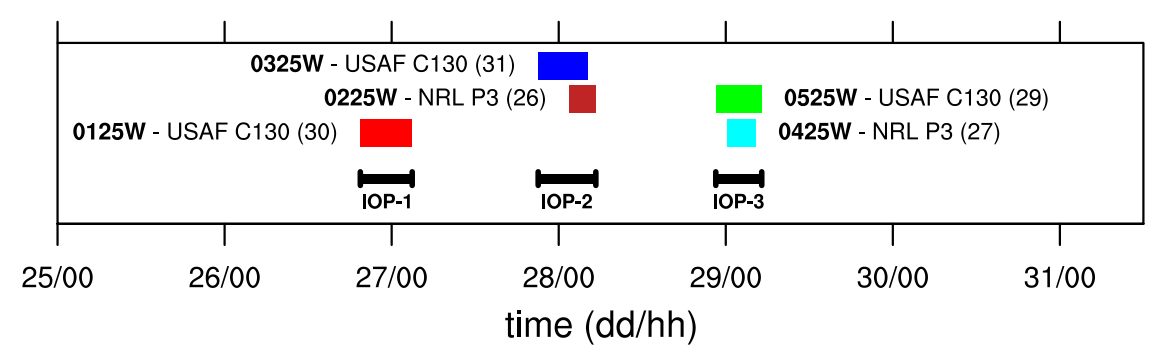

FIG. 1. Approximate on-station (data collection) times for TCS025 aircraft missions: 0125W$0525 \mathrm{~W}$. The numbers in parentheses correspond to the number of dropwindsondes deployed during each mission.

misaligned such that system-relative flow (low- to midtropospheric vertical wind shear) was larger compared to a vertically aligned circulation. These factors combined to limit organization, which allowed midlevel lowequivalent potential temperature $\left(\theta_{e}\right)$ air to impact the inner-core thermodynamic environment. This in turn weakened convection and hindered further development. An outline for the remainder of this paper is as follows: the data and methodology for this study are presented in section 2, section 3 details the synoptic and convective evolution of TCS025, a mesoscale analysis of the aircraft-based in situ observations is contained in section 4, and a discussion of the findings and conclusions are presented in section 5.

\section{Data and methodology}

Aircraft missions during TCS025 were conducted by the U.S. Air Force (USAF) 53rd Weather Reconnaissance Squadron (Hurricane Hunters) WC-130J and the Naval Research Laboratory (NRL) P-3 over three intensive observing periods (IOPs) (Fig. 1). Both aircraft collected flight-level data and the WC-130J retrieved surface wind speeds and rain rates underneath the flight track using the onboard Stepped Frequency Microwave Radiometer (SFMR; Uhlhorn et al. 2007).

In total, 143 GPS dropwindsondes (Hock and Franklin 1999) were deployed during the five aircraft missions into TCS025 and the surrounding environment (Fig. 1). Dropwindsondes were deployed from about a $10-\mathrm{km}$ altitude during the three WC-130J missions. Since the P-3 was tasked to investigate convective features, its flight tracks were far more irregular so dropwindsondes were deployed with variable spacing and generally from below $3 \mathrm{~km}$. All dropwindsonde data were quality controlled by the Earth Observing Laboratory (EOL) at the National Center for Atmospheric Research (NCAR; Young et al. 2009a,b).

Dropwindsonde data were also used to analyze the vertical alignment of the storm-relative circulation based on the method used by Davis and Ahijevych (2012). To correct for sampling bias, Davis and Ahijevych (2012) first averaged the observations by storm quadrant. However, because of the relatively weak and highly asymmetric wind structure of TCS025, this procedure did not yield consistent results so all dropwindsonde data were used in this study.

The Electra Doppler Radar (ELDORA; Hildebrand et al. 1996; Wakimoto et al. 1996), which was mounted on the tail of the P-3 during T-PARC/TCS-08 (Lee et al. 2009), allowed for an examination of the precipitation and circulation structure of the nondeveloping TCS025 system over two consecutive days. Radial velocity data were corrected for aircraft motion by using the method described in Testud et al. (1995). The reflectivity and radial velocity fields underwent an additional quality control step to remove radar artifacts, noise, ground clutter, etc., using an automated procedure described by Bell et al. (2013).

In addition to the observations collected during the IOPs, digital Multifunctional Transport Satellite (MTSAT) IR brightness temperatures at $0.05^{\circ}$-spatial and 30-min-temporal resolutions were azimuthally and radially averaged in cylindrical coordinates based on manually determined center positions for TCS025. The cloud-top temperatures were used to infer the average convective characteristics of the TCS025 environment. The MTSAT IR brightness temperatures were also interpolated to the time and location of the dropwindsondes to construct average dropwindsonde vertical profiles based on IR brightness temperature values.

The European Centre for Medium-Range Weather Forecasts (ECMWF) Year of Tropical Convection (YOTC; Waliser et al. 2012) gridded analysis with $\sim 0.25^{\circ}$ horizontal resolution at 6-h intervals was used to analyze the synoptic background and evolution of TCS025. Earth-relative circulation center positions were identified from an examination of 850-hPa ECMWF analysis streamlines for the time period encompassing aircraft observations. When a closed circulation was not 
(a)

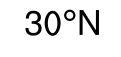

$30^{\circ} \mathrm{N}$

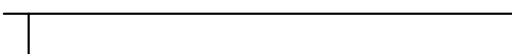

$28^{\circ} \mathrm{N}$

$\mathrm{N}-$
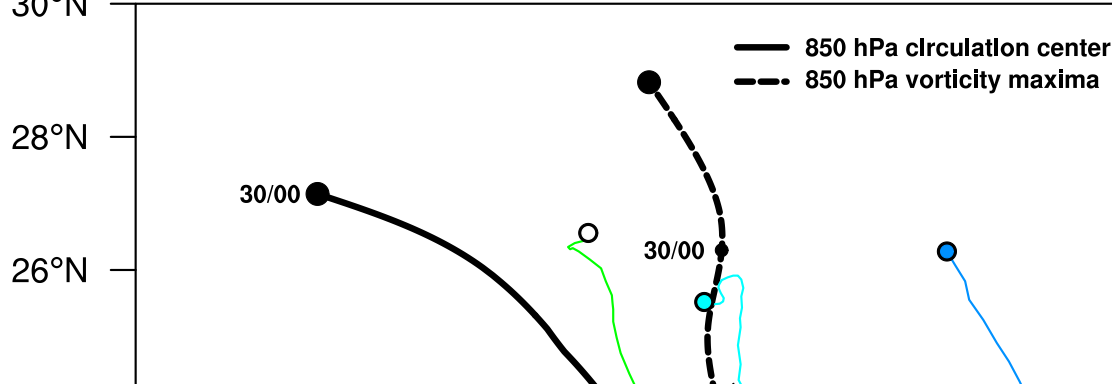

$22^{\circ} \mathrm{N}$

N

. 
TABLE 1. Configurations used for the 5- and 2-km (horizontal grid spacing) SAMURAI analyses. Listed are the background error standard deviation values for temperature $(T)$, water vapor mixing ratio $\left(q_{v}\right)$, dry-air density $\left(\rho_{a}\right)$, and moist-air-density-weighted wind components $(\rho u, \rho v$, and $\rho w)$. The Gaussian recursive filter lengths correspond to grid points in the horizontal $(i, j)$ and vertical $(k)$ directions.

\begin{tabular}{ccccccccc}
\hline & Vertical grid spacing $(\mathrm{m})$ & $T(\mathrm{~K})$ & $q_{v}\left(\mathrm{~g} \mathrm{~kg}^{-1}\right)$ & $\rho_{a}\left(\mathrm{~kg} \mathrm{~m}^{-3}\right)$ & $\rho u, \rho v\left(\mathrm{~kg} \mathrm{~m}^{-2} \mathrm{~s}^{-1}\right)$ & $\rho w\left(\mathrm{~kg} \mathrm{~m}^{-2} \mathrm{~s}^{-1}\right)$ & $i, j$ filter & $K$ filter \\
\hline $5 \mathrm{~km}$ & 100 & 3 & 3 & 3 & 10 & 1 & 8 & 2 \\
$2 \mathrm{~km}$ & 100 & 3 & 3 & 3 & 15 & 10 & 6 \\
\hline
\end{tabular}

The ECMWF analysis was also used to calculate the deep-layer (200-850 hPa) and lower-tropospheric (500$850 \mathrm{hPa}$ ) environmental vertical wind shear by employing the method of Davis et al. (2008). The irrotational and nondivergent components of the vertical wind shear associated with the disturbance were removed from the total vertical wind shear out to a radius of $450 \mathrm{~km}$, and vertical wind shear was defined as the difference between the resultant wind vectors at the center position. Since the TCS025 circulation remained relatively shallow and there were periods when it was not well defined, the distinction between TCS025 and the surrounding environment was not always clear. This may have impacted the environmental vertical wind shear calculations during these periods.

To achieve as accurate an assessment of the true atmospheric state as possible, data collected during the IOPs were combined with the ECMWF analysis using the Spline Analysis at Mesoscale Utilizing Radar and Aircraft Instrumentation (SAMURAI) analysis technique (Bell et al. 2012; Foerster et al. 2014), which provides a maximum likelihood estimate of the atmospheric conditions through the minimization of a variational cost function. Although dropwindsonde data were available for assimilation into the ECMWF YOTC analysis fields, the flight-level and ELDORA dual-Doppler radar data were not. SAMURAI analyses for IOP-2 and IOP-3 were conducted in the stormrelative frame using two Cartesian analysis domains that (i) encompassed all observations (5-km horizontal and 100-m vertical grid spacing), and (ii) encompassed only the ELDORA domain (2-km horizontal and $100-\mathrm{m}$ vertical grid spacing). Because of the large disparity between the typical spacing of ELDORA radial velocity observations and the WC-130J dropwindsondes, the use of the ECMWF background field allowed for a $5-\mathrm{km}$ analysis without the need for excessive smoothing. Furthermore, comparisons with additional analyses conducted without the use of a background field (not shown), revealed minimal differences in the representation of the circulation structure. Additional specifications for the SAMURAI analyses used in this study are given in Table 1 and in Penny (2013, 46-47).

\section{System evolution}

The TCS025 disturbance formed on the eastern periphery of a low-level trough over the subtropical western North Pacific, and initially followed a track toward the southeast before turning toward the northnorthwest (Fig. 2a). Convection associated with TCS025 was episodic and marked by development and decay of numerous mesoscale convective systems (MCS) that occurred in the general region (Fig. 2) where TCS025 would later develop. Convective features associated with TCS025 that could be loosely classified as MCSs were identified and tracked throughout its evolution. Convection organized into a broad MCS (MCS-A) centered near $22^{\circ} \mathrm{N}, 152^{\circ} \mathrm{E}$ that reached peak intensity measured by IR brightness temperature by 1130 UTC 25 August (Figs. 2 and 8). This MCS moved quickly to the southeast, and by 0000 UTC 26 August only weak and relatively disorganized convection remained. Deep convection continued to develop and decay, and at 0645 UTC 26 August, MCS-D formed near $20^{\circ} \mathrm{N}, 150^{\circ} \mathrm{E}$, which remained the primary area of convection through the time of the first aircraft operation (Fig. 1).

At 0000 UTC 27 August (Fig. 3), the low-level trough extended from the northwest to southeast and consisted of three circulations (Fig. 3c). Two tropical uppertropospheric trough (TUTT) cells (Fig. 3b) were in close proximity to the low-level trough. At this time, the 200-850-hPa environmental vertical wind shear was northerly at $15 \mathrm{kt}\left(1 \mathrm{kt}=0.5144 \mathrm{~m} \mathrm{~s}^{-1}\right)$ (Fig. 7). Upperlevel diffluence between the TUTT cells to the north coincided with the area of deep convection associated with MCS-D (Fig. 3a) that was near the central low-level circulation (L2) at $22^{\circ} \mathrm{N}, 150^{\circ} \mathrm{E}$ (Fig. 3c). During the ensuing hours, MCS-D fluctuated in intensity and structure and moved southward (Fig. 2a), presumably due to the northerly flow aloft between the two TUTT cells (Fig. 3b). There was limited convection along the eastern periphery of the low-level trough close to the low-level circulation L3 (Fig. 3a). At 0845 UTC 27 August, MCS-D dissipated (see Fig. 2).

Over the next $24 \mathrm{~h}$ (Fig. 4), the low-level circulation L3 weakened and became absorbed by L2 to the west 
(a)

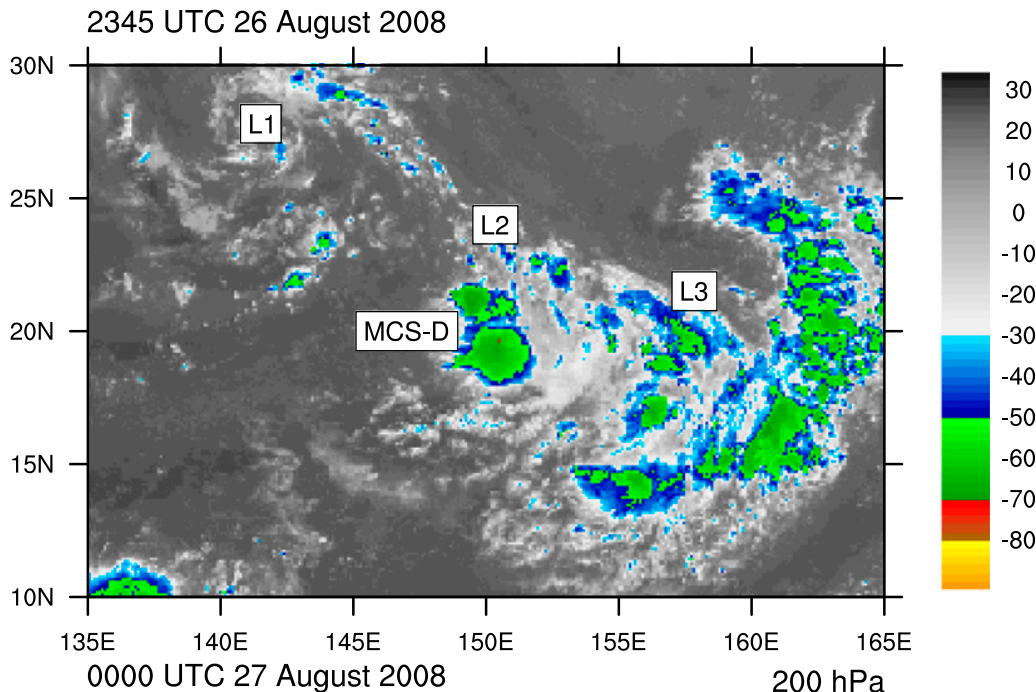

(b)

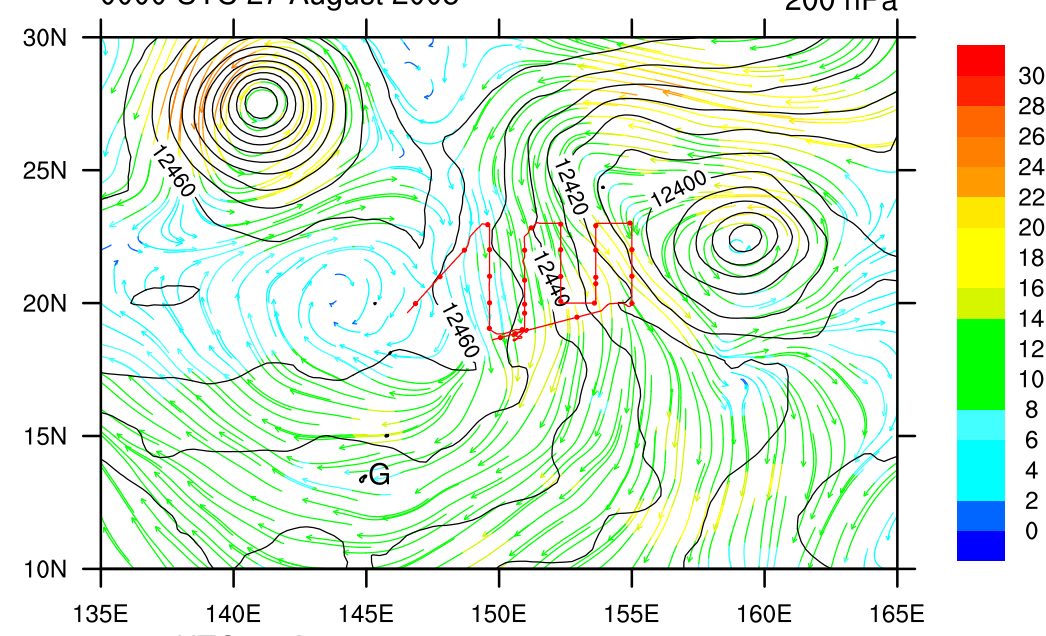

(c)

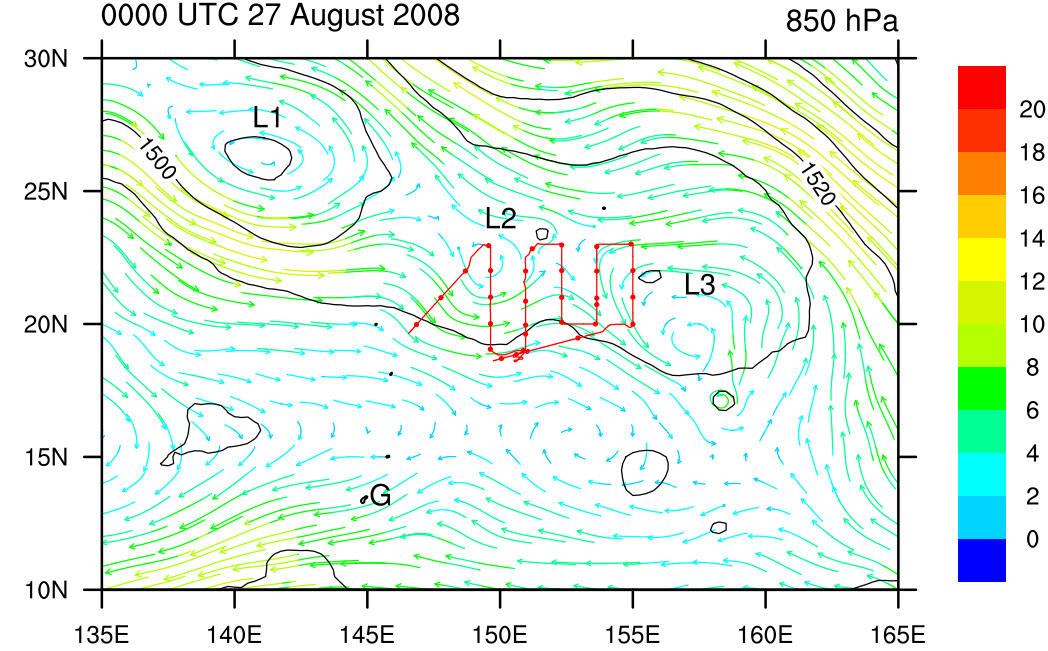

FIG. 3. (a) MTSAT IR brightness temperature $\left({ }^{\circ} \mathrm{C}\right)$ at 2345 UTC 26 Aug. (b), (c) Horizontal wind vectors $\left(\mathrm{m} \mathrm{s}^{-1}\right.$, colored scale on right) and geopotential heights ( $\mathrm{m}$, black contours) at 200 and $850 \mathrm{hPa}$ from ECMWF analysis valid at 0000 UTC $27 \mathrm{Aug}$, respectively. The location of MCS-D is annotated in (a) and the red line and red circles in (b) and (c) correspond to the flight track and dropwindsonde deployment locations for WC-130J flight $0125 \mathrm{~W}$. Low-level circulations are labeled L1, L2, and L3 in (a) and (c), and G marks the location of Guam. 
(a)

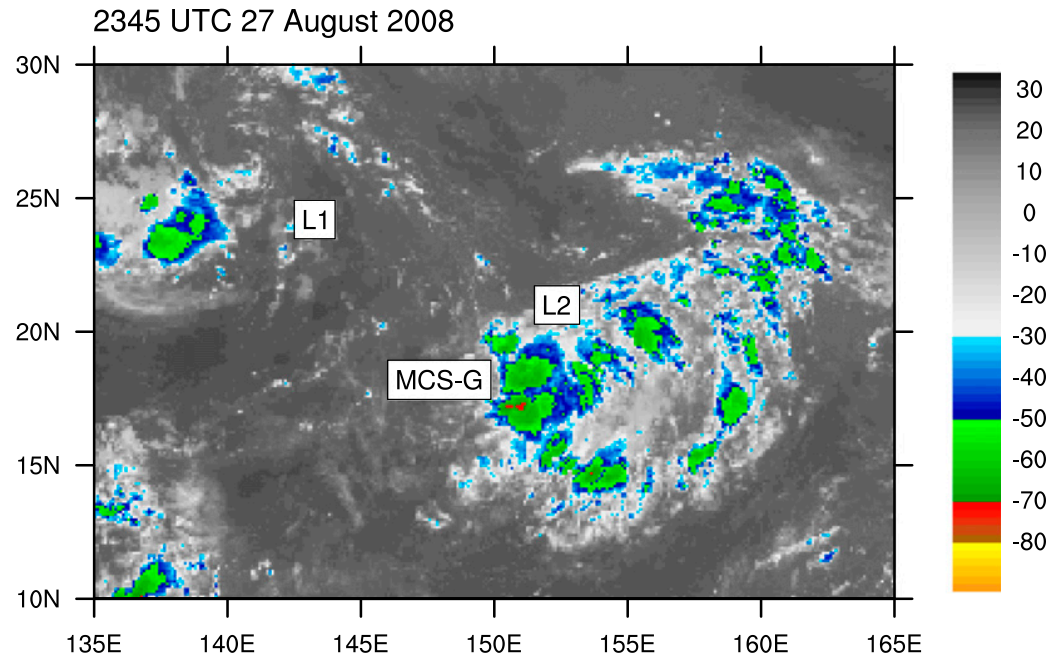

(b)

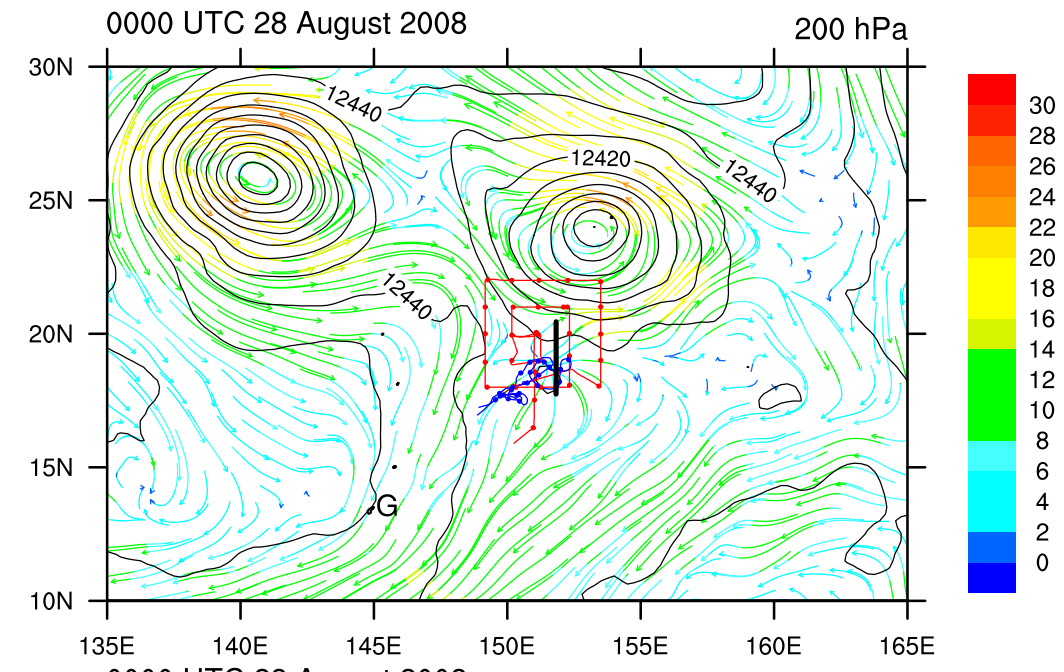

(c)

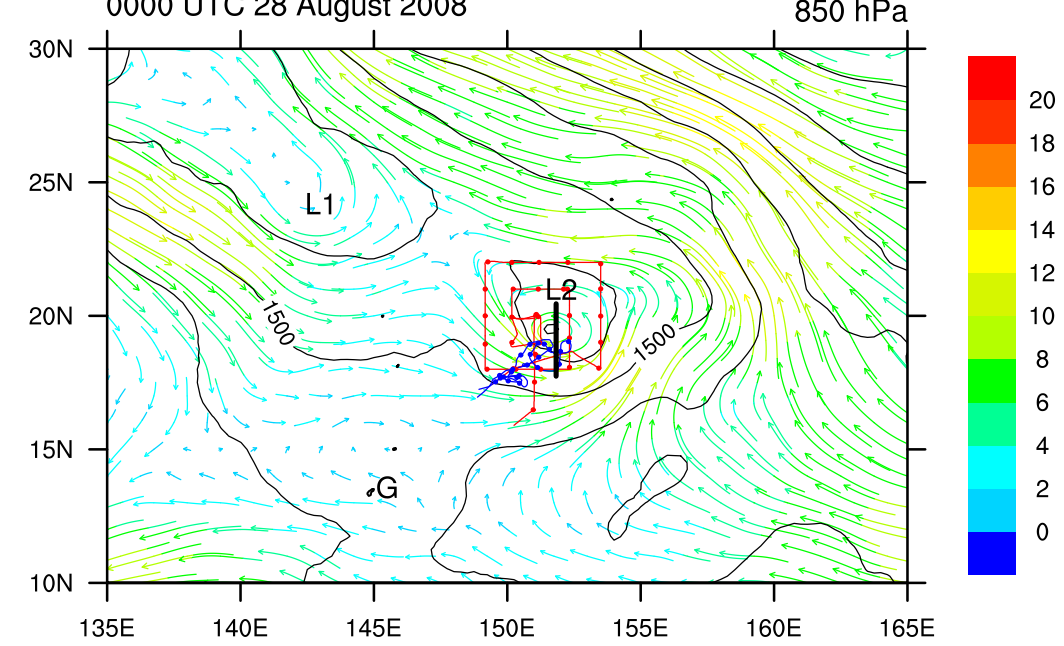

FIG. 4. As in Fig. 3, but MTSAT IR brightness temperature valid at 2345 UTC 27 Aug and ECMWF analysis valid at 0000 UTC 28 Aug. MCS-G is annotated in (a) and flight track and dropwindsonde deployment locations for WC-130J flight $0325 \mathrm{~W}$ are shown in (b) and (c) with blue line and circles corresponding locations for P-3 flight $0225 \mathrm{~W}$. The south-north vertical cross section shown in Fig. 14 is marked by a black line in (b) and (c). 
(cf. Figs. 3c and 4c). At this time, the eastern edge of the low-level trough near $155^{\circ} \mathrm{E}$ was marked by strong confluence and southerly low-level winds as L2 intensified (Fig. 4c). Convection (Fig. 4a) remained relatively disorganized and weak until after 1200 UTC 27 August when the easternmost TUTT cell moved north-northeast of L2 (Figs. 4b,c). At 1045 UTC 27 August, MCS-G formed near $20^{\circ} \mathrm{N}, 150^{\circ} \mathrm{E}$, which was close to the location where MCS-D had developed the day before (Fig. 2). Similar to MCS-D, MCS-G moved southward before dissipating by 1145 UTC 28 August (Fig. 2). The MCS-G and its surrounding environment were the primary foci of IOP-2. The environmental vertical wind shear magnitude was beginning to decline at this time and reached a minimum of about $5 \mathrm{kt}$ at 1200 UTC 28 August (see Fig. 7).

After the dissipation of MCS-G, convection remained disorganized and weak until about 1800 UTC 28 August when MCS-H formed near $18^{\circ} \mathrm{N}, 154^{\circ} \mathrm{E}$ (Fig. 2), which was in confluent flow east of L2. By 0000 UTC 29 August (Fig. 5), the eastern TUTT cell weakened considerably (Fig. 5b) and was well northwest of L2 (Fig. 5c) and an upper-level anticyclone was building above L2. Despite the development of an anticyclone aloft, the environmental vertical wind shear began to increase (see Fig. 7) due to the strengthening of the southerly flow along the eastern side of the low-level circulation. An area of deep convection (Fig. 5a) was also present near a region of upper-level diffluence east of the TUTT cell and extended farther east to the upper-level ridge (MCS-I and MCS-J in Fig. 2). As TCS025 began to move northward following 1200 UTC 28 August, the earth-relative circulation center and vorticity maxima positions began to separate considerably (see Fig. 2a), and the majority of the convection remained near the vorticity maxima position, east of the low-level earth-relative circulation center.

By 0000 UTC 30 August (Fig. 6), the low-level circulation of TCS025 was no longer closed in both the ground- and storm-relative frames and moved rapidly northwestward as a low-level ridge strengthened to the south and east of TCS025 (Fig. 6c). Strong confluent southwesterly flow coincided with an area of increased convective activity to the south-southeast of the L2 circulation. A cyclonically banded cloud structure (Fig. 6a) became evident in MTSAT brightness temperature and a broad anticyclone existed aloft (Fig. 6b).

Northerly 200-850-hPa vertical wind shear (Fig. 7a) continued to increase in magnitude on 30 August as a result of the rapid northward translation of the system and the impinging upper-level flow of another TUTT cell approaching from the east (not shown). By 1200 UTC 30 August, convection that defined TCS025 became disorganized and weak, and following 1800 UTC 30 August the cloud structure of TCS025 began to dissipate (not shown). Between 31 August and 1 September, the remnants of TCS025 underwent some extratropical development upon encountering a weak baroclinic zone to the north (Davis et al. 2013).

Since the Raymond et al. (2011) study concluded that horizontal shear was an important factor in the nondevelopment of TCS025, the evolution of the average normalized Okubo-Weiss $(\mathcal{N})$ parameter (Raymond et al. 2011) was examined (Fig. 7b). The $\mathcal{N}$ parameter allows for an assessment of the relative importance of the rotational and deformational components of the horizontal flow. Values of $\mathcal{N}$ range from -1 to +1 . Positive values indicate a larger rotational component of the flow and negative values indicate that horizontal shear is large, which may prevent the consolidation of vorticity and indicate the circulation of an incipient disturbance is less protected from the detrimental effects of dry air in the surrounding environment (Raymond et al. 2011; Tory et al. 2013). The evolution of average $\mathcal{N}$ (Fig. 7b) indicates that the TCS025 environment was dominated by large horizontal deformation throughout its evolution. As the vertical wind shear magnitude decreased (Fig. 7a) following IOP-2, $\mathcal{N}$ began to trend positive in the low levels, perhaps indicating that the system was experiencing some organization. However, the increase in $\mathcal{N}$ was brief and did not extend up to $500 \mathrm{hPa}$, which indicates that the protective region of the pouch was quite shallow (Montgomery et al. 2010).

The convective intensity of the identified MCSs, defined as the brightness temperature area $<-65^{\circ} \mathrm{C}$ normalized by the brightness temperature area $<-35^{\circ} \mathrm{C}$, varied systematically with the diurnal cycle (Fig. 8). Convective intensity was highest around 1800 UTC daily, which approximately corresponds to the early morning oceanic convective maximum time (Yang and Smith 2006; Park et al. 2011). The minimum in convective intensity occurred shortly after 0000 UTC, which also corresponded to the time that the majority of aircraft observations of TCS025 were collected (see Fig. 1).

To examine the average convective characteristics throughout the evolution of TCS025, the IR brightness temperatures were radially averaged (Fig. 9) relative to the 850 -hPa vorticity maxima positions. During the period when the vorticity maxima were collocated with the low-level circulation center, the majority of convection formed south of the center position, which was in the downshear direction (Fig. 7a). Convection downshear of the low-level center is consistent with previous studies that examined the tropical cyclone convective response 
(a)

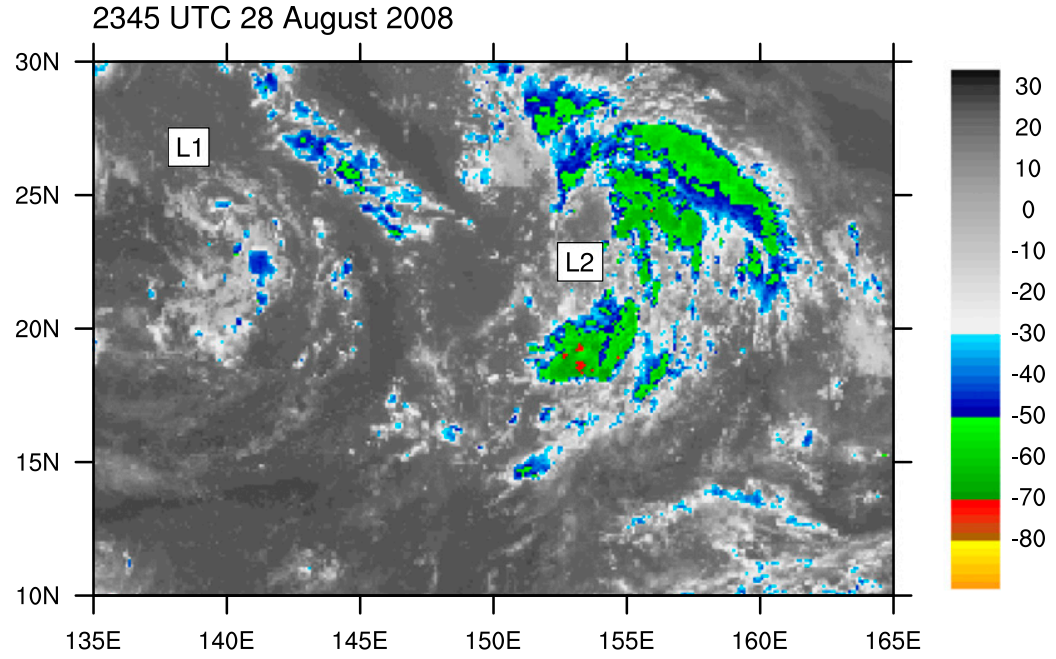

(b)

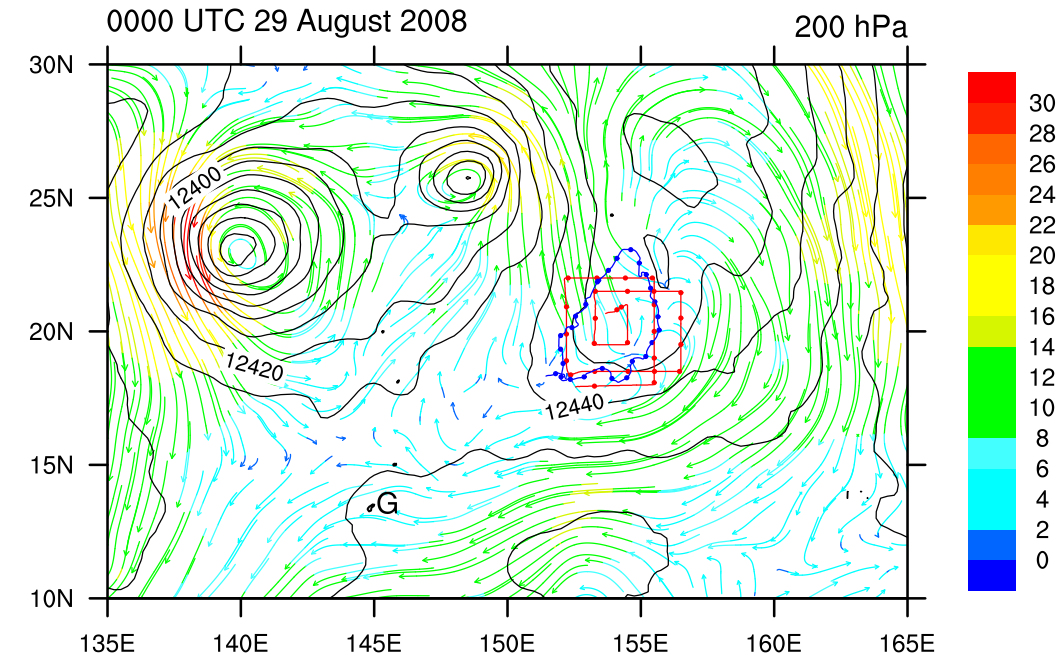

(c)

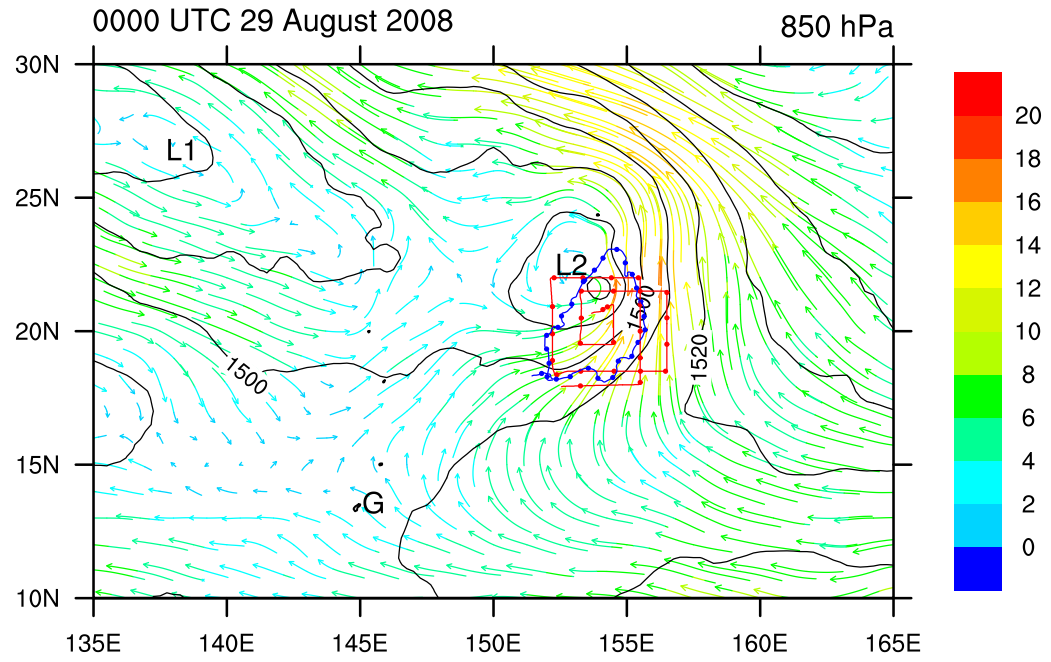

FIG. 5. As in Fig. 3, but MTSAT IR brightness temperature valid at 2345 UTC 28 Aug and ECMWF analysis valid at 0000 UTC 29 Aug. The red and blue tracks with dropwindsonde locations correspond to WC-130J flight $0525 \mathrm{~W}$ and P-3 flight $0425 \mathrm{~W}$, respectively. 
(a)

(b)
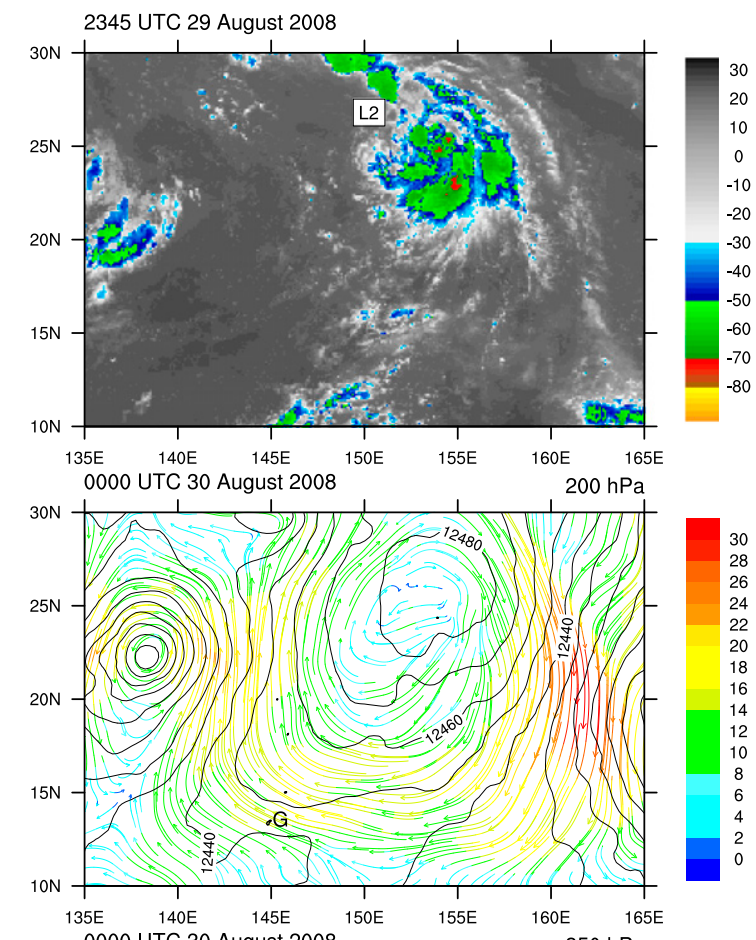

(c)

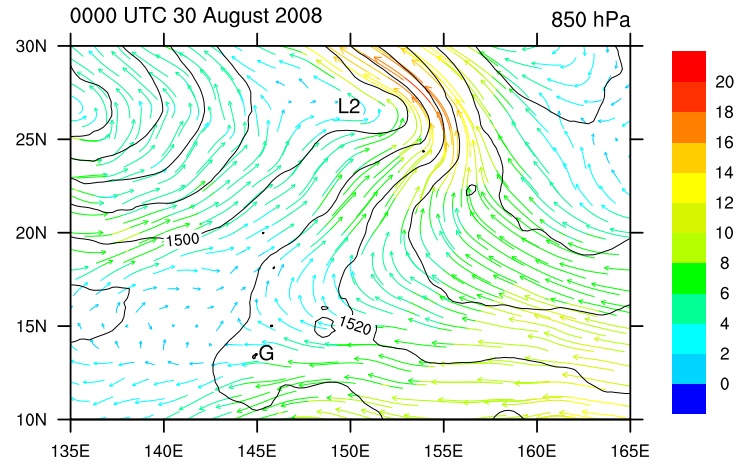

FIG. 6. As in Fig. 3, but MTSAT IR brightness temperature valid at 2345 UTC 29 Aug and ECMWF analysis valid at 0000 UTC 30 Aug.

to vertical wind shear (Jones 1995; Frank and Ritchie 1999). Although MCS-like features that formed near the convective maximum time (short dashed lines in Fig. 9) were present at the time of each IOP, the radially averaged IR brightness temperature indicates that convection was not as concentrated nor intense leading up to IOP-3. In addition, the convective area remained small until well after 0000 UTC 29 August, which was later than the previous two days.

\section{Mesoscale analysis of in situ observations}

To examine the mesoscale structure of the TCS025 disturbance, the in situ observations were examined and SAMURAI analyses were conducted for each IOP (Fig. 1) using dropwindsonde data, flight-level data,
ELDORA dual-Doppler radar data (when available), and the ECMWF YOTC analysis fields. Since the sampling coverage relative to the circulation center was superior during IOP-2, data collected during this IOP will receive the majority of attention in the analysis.

\section{a. IOP-1 (1930 UTC 26 August-0257 UTC 27 August)}

During IOP-1 centered at 0000 UTC 27 August, the WC-130J conducted a "lawnmower" flight pattern (Fig. 10) and deployed dropwindsondes to sample the environment of MCS-D (Fig. 3) that was beginning to decay while propagating southward. Although earthrelative circulation center positions were determined as a function of height from dropwindsonde data, uncertainties in the center positions were too large to evaluate the vertical alignment of the circulation due to incomplete sampling of the circulation. That said, the dropwindsonde center-finding method suggested two low-level circulations (not shown) that agreed relatively well with the ECMWF analysis (Fig. 3): the center providing the maximum average tangential wind near the surface corresponded to circulation L2, whereas in the midlevels it was closer to the location of L3.

\section{b. IOP-2 (2103 UTC 27 August-0520 UTC 28 August)}

At the time of IOP-2, the low-level circulation was beginning a turn toward the northeast (Fig. 2a). Because the first WC-130J aircraft mission had identified a circulation center, the second mission was flown as a "square spiral" centered on the estimated circulation center (Fig. 11). Similar to the previous day, a large MCS (MCS-G) was present south of the circulation center (Fig. 11).

An examination of the dropwindsonde winds from IOP-2 reveals that the circulation of TCS025 was highly asymmetric (Fig. 12). The strongest low-level winds were westerly and southwesterly in the south and southeast portions of the WC-130J flight domain. Over the western portion of the domain, the low-level circulation was relatively weak. The strongest midlevel winds were northerly and northwesterly on the western side of the midlevel circulation near $18.5^{\circ} \mathrm{N}, 151^{\circ} \mathrm{E}$ (Fig. 12).

Dropwindsonde coverage (Figs. 11 and 12) relative to the circulation center was much more evenly distributed than during IOP-1 or IOP-3. The dropwindsonde-based center analysis in the storm-relative frame reveals that the circulation centers were poorly aligned in the vertical. The low-level circulation tilted toward the east with height, while above $2 \mathrm{~km}$ the circulation tilted toward the southeast (Fig. 12). 
(a)

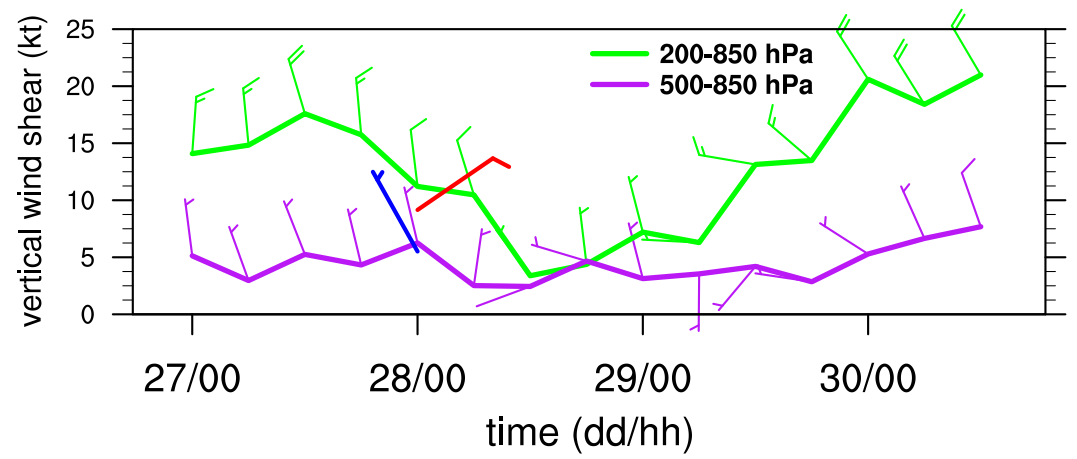

(b)

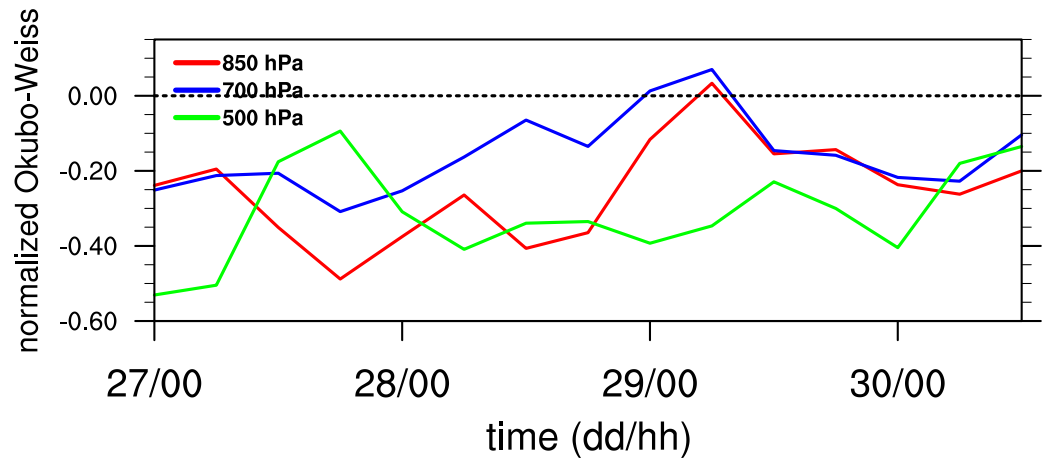

FIG. 7. (a) Deep-layer (200-850 hPa, green, kt) and low- to midlevel (500-850 hPa, purple, kt) environmental vertical wind shear and direction (wind barbs, 1 full barb $=10 \mathrm{kt}$ ) computed using the ECMWF analysis (see text for details). Also shown are wind barbs for the pseudoaligned (blue barb, $5.4 \mathrm{kt}$ ) and misaligned (red barb, $9.3 \mathrm{kt}$ ) mesoscale system-relative flow from the 0000 UTC 28 Aug SAMURAI analysis (see text for details). (b) Time series of the boxaverage $\left( \pm 3^{\circ}\right.$ from vorticity maxima locations) normalized Okubo-Weiss parameter from the ECMWF analysis at pressure levels shown in inset.

Storm-relative circulation center positions were also identified as a function of height using streamlines from the SAMURAI analysis (Fig. 12), which included ELDORA Doppler radar data. The SAMURAI analysis revealed a fractured circulation structure in the vertical; the low-level circulation was located near $19.5^{\circ} \mathrm{N}, 152.5^{\circ} \mathrm{E}$ and only extended to $2-\mathrm{km}$ height, and the circulation centers between $2.5-$ and $6-\mathrm{km}$ height were a considerable distance south-southwest of the low-level circulation.

The differences in center positions between the dropwindsonde method and the SAMURAI analysis (Fig. 12) may be partly a result of not correcting for the sampling bias in dropwindsonde coverage (see section 2). However, additional tests revealed little difference in the dropwindsonde-derived center positions when P-3 dropwindsondes were excluded from the calculation (not shown), suggesting the impact from sampling bias was minimal for this case. Instead, contrasts in horizontal resolution may have contributed to the differences in circulation center positions. Whereas dropwindsondes were generally deployed with $100-\mathrm{km}$ spacing, the SAMURAI analysis had 5-km grid spacing.
Thus, the scales of motion sampled by the dropwindsondes were most likely larger than that resolved by the SAMURAI analysis, especially over the area impacted by the ELDORA radar winds. Nevertheless, both sources identify a low-level center that is displaced north of a midlevel center.

The SAMURAI analysis for IOP-2 also reveals an asymmetric vortex structure in the low and midlevels (Fig. 13). The circulation in the midtroposphere was stronger than the low-level circulation, which is indicative of a cold-core circulation. At this time, the midlevel circulation center (red dot in Fig. 13) was positioned $\sim 110 \mathrm{~km}$ to the south-southwest of the lowlevel circulation center (black dot in Fig. 13). Low- to midtropospheric vertical wind shear resulted from the relative locations of the mid- and low-level circulations; northeasterly flow near $19^{\circ} \mathrm{N}, 151.2^{\circ} \mathrm{E}$ in the northwest quadrant of the midlevel circulation (Fig. 13a) was positioned nearly above the center of the low-level circulation.

The potential impact of the vertical misalignment was examined by comparing the average mesoscale vertical wind shear (system-relative flow) in the storm-relative 


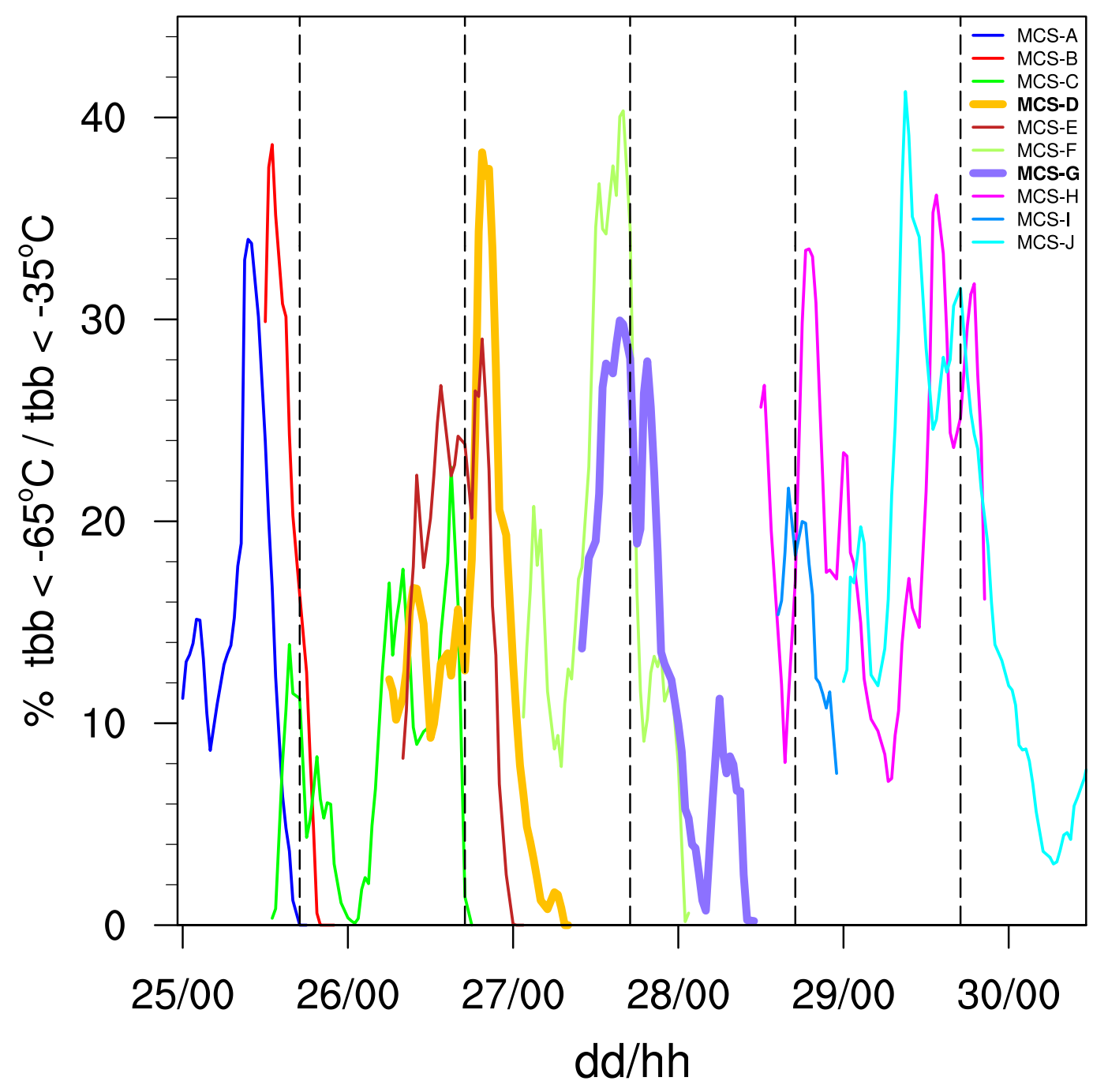

FIG. 8. Ratio expressed as a percentage of area with MTSAT IR brightness temperatures $<-65^{\circ} \mathrm{C}$ to that $<-35^{\circ} \mathrm{C}$ for MCSs that developed within the environment of TCS025. Dashed vertical black lines indicate the approximate time of the expected early morning convective maximum.

SAMURAI analysis between 5 - and $1.5-\mathrm{km}$ height (Fig. 13) with an identical pseudo-aligned circulation (i.e., as if the mid- and low-level circulations were vertically aligned). The system-relative flow for the misaligned circulation was computed as the difference between the 5- and $1.5-\mathrm{km}$ box average wind vectors centered over the $1.5-\mathrm{km}$ circulation (dashed black box vs solid black box in Fig. 13), whereas the pseudoaligned system-relative flow was defined as the difference between the 5- and $1.5-\mathrm{km}$ box average wind vectors centered on their respective circulation centers (solid red box vs solid black box in Fig. 13). The systemrelative flow for the misaligned circulation was $9.3 \mathrm{kt}$ from the northeast (see Fig. 7a), whereas the systemrelative flow for the pseudo-aligned circulation was only
$5.4 \mathrm{kt}$ from the north-northwest. This indicates that the misalignment of the circulation resulted in a larger system-relative flow then if the circulation had been vertically aligned. The environmental $500-850-\mathrm{hPa}$ vertical wind shear was very similar in magnitude and direction to the pseudo-aligned case during this time (Fig. 7a), which illustrates that the low-level vertical wind shear experienced locally by the system (on the mesoscale) due to misalignment can be considerably different from the computed environmental vertical wind shear.

To analyze the impact of including the ELDORA radial velocity observations in the SAMURAI analysis, south to north vertical cross sections through the midand low-level circulation centers of the ECMWF 


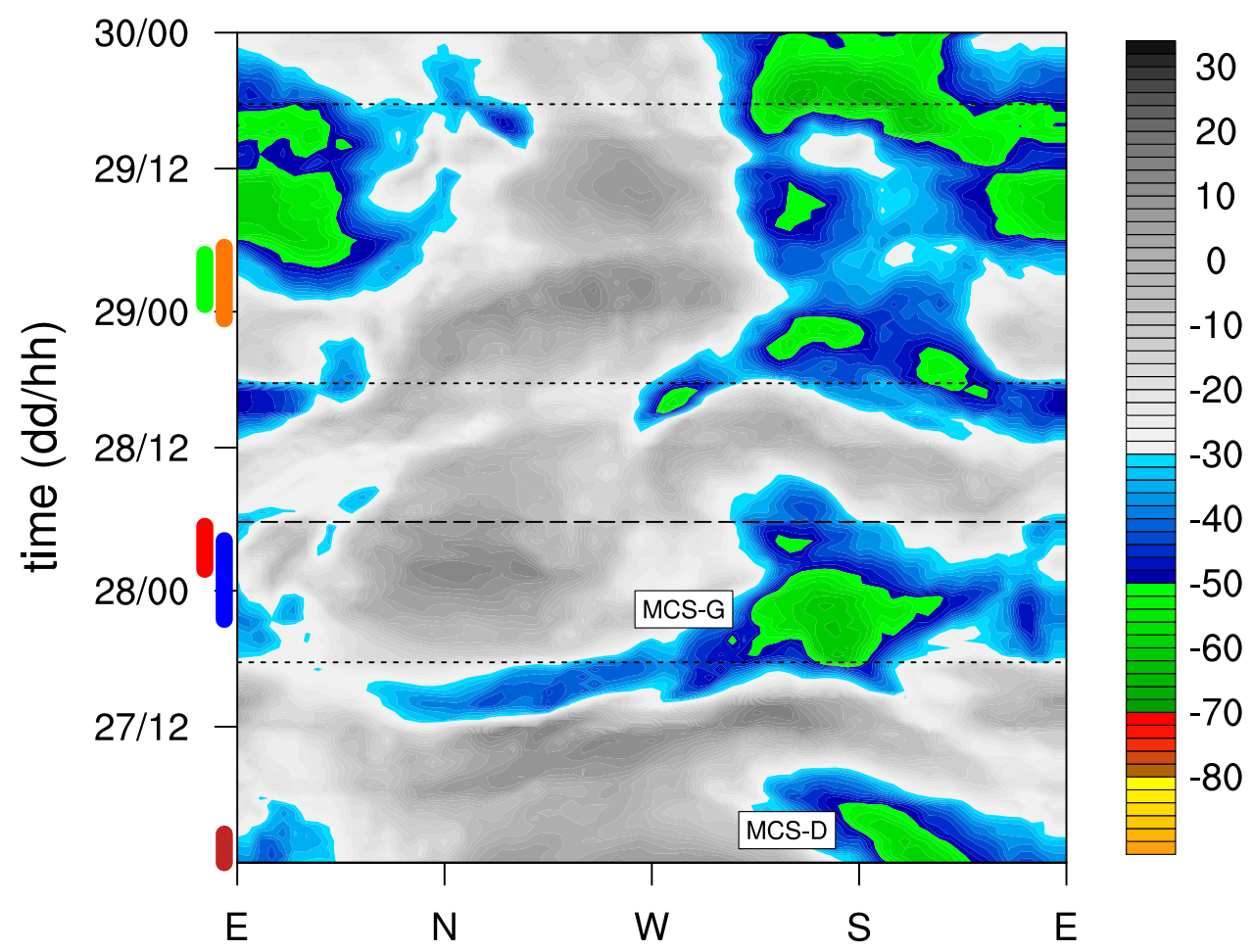

FIG. 9. Radially averaged $\left(0^{\circ}-3^{\circ}\right)$ half-hourly MTSAT IR brightness temperatures $\left({ }^{\circ} \mathrm{C}\right.$, shading) relative to the ECMWF 850-hPa vorticity maximum positions of TCS025. Colored bands along the ordinate represent WC-130J and P-3 aircraft missions flown into TCS025 with brown, blue, and orange corresponding to the WC-130J missions and red and green corresponding to the P-3 missions. Abscissa axis labels correspond to directions along the azimuth. Short dashed horizontal lines mark the approximate time of diurnal convective maximum (1800 UTC) and long dashed horizontal line denotes the ending time of the $0225 \mathrm{~W}$ P-3 mission. The brightness temperature features associated with MCS-D and MCS-G are annotated.

analysis background field (Fig. 14a) and the SAMURAI analysis (Fig. 14b) were compared. The ECMWF analysis (Fig. 14a) possessed a much stronger lowlevel circulation that tilted southward into the midtroposphere. In contrast, the SAMURAI analysis (Fig. 14b) depicted a strong midlevel circulation near $6-\mathrm{km}$ height that was almost entirely separate from a shallow and much weaker low-level circulation to the north. The low-level wind field of the SAMURAI analysis more closely resembled the broad trough observed the day before (see Fig. 3c) rather than the well-defined low-level circulation of the ECMWF analysis. The low-level circulation in the SAMURAI analysis was outside the range of the ELDORA Doppler radar (black lines below the abscissa in Fig. 14b), so the vorticity magnitude was primarily determined by the dropsondes in that region. The lack of radar data results in a higher uncertainty in the vorticity magnitude, but the analysis suggests that the low-level circulation is weaker than that in the ECMWF analysis.
The divergence profile near the low-level vorticity feature in the SAMURAI analysis (Fig. 14b) appears to be a result of Ekman pumping, with frictionally induced convergence within the boundary layer and divergence immediately above the boundary layer. Midlevel convergence was collocated with the midlevel vorticity feature to the south, typical of a mesoscale convective vortex (MCV; Raymond and Jiang 1990; Bartels and Maddox 1991; Houze 2004). In addition, there was a positive temperature anomaly in the SAMURAI analysis above $6.5-\mathrm{km}$ height over a negative low-level temperature anomaly (not shown), which is also characteristic of the thermal structure of a balanced midlevel vortex (Chen and Frank 1993). Winds in the plane of the cross section were northerly with some positive vertical motion extending from an area of midtropospheric low$\theta_{e}$ air associated with the TUTT toward the midlevel vorticity feature, and low-level southerlies were present south of the midlevel vorticity feature.

Based on the SAMURAI (ELDORA) divergence profile (Fig. 14b) and the ELDORA reflectivity pattern 


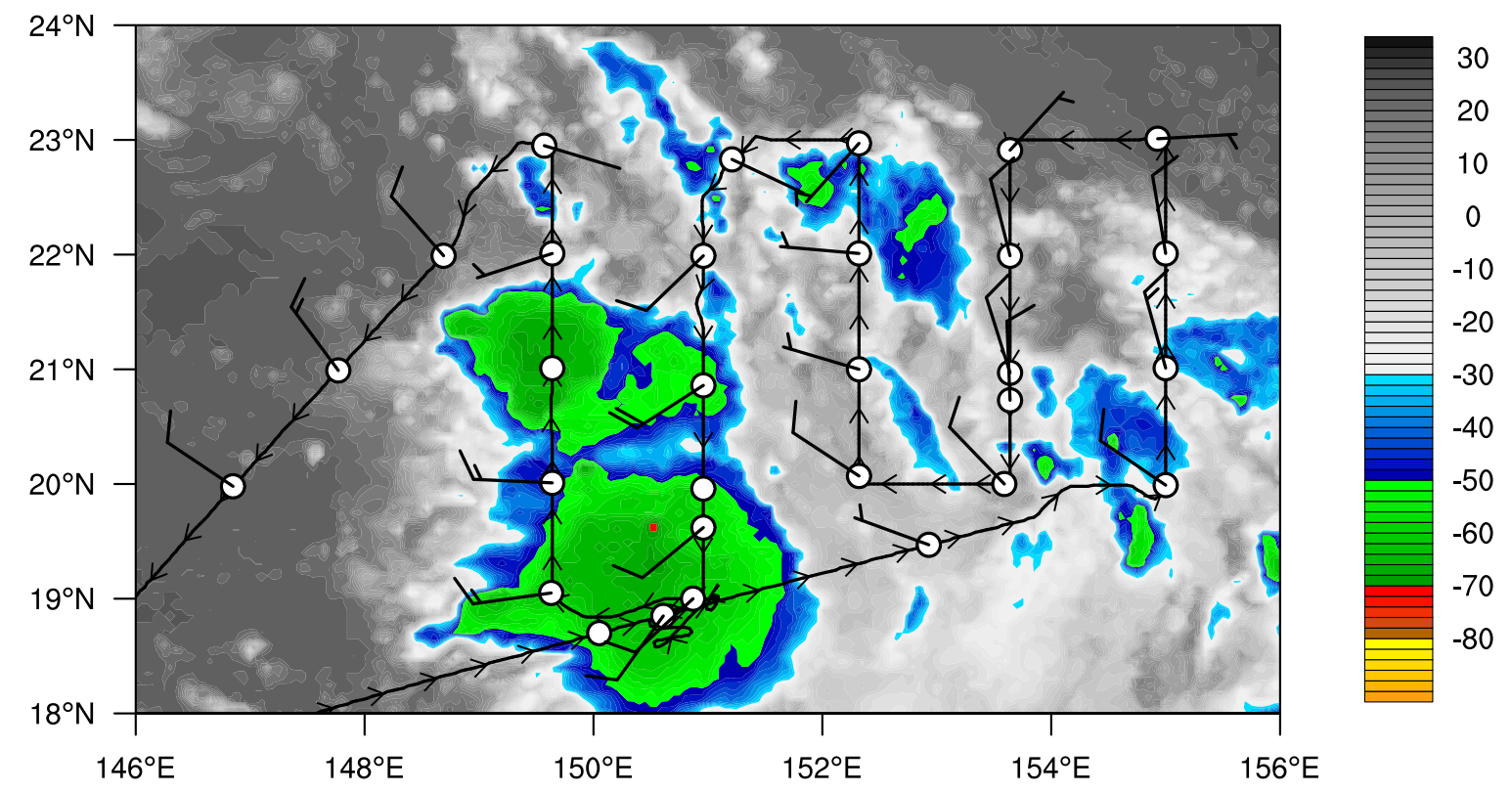

FIG. 10. MTSAT IR brightness temperature $\left({ }^{\circ} \mathrm{C}\right.$, shading) valid at 2345 UTC 26 Aug. The WC-130J flight track (black line) and dropwindsonde deployment locations (white circles) are shown with wind barbs corresponding to $1500 \mathrm{~m}$ height $(1 \mathrm{full}$ barb $=10 \mathrm{kt})$ for IOP-1 (0125W).

at 5-km height (Fig. 15), the region surrounding the midlevel circulation had large areas of stratiform precipitation during IOP-2. Stratiform precipitation processes likely contributed to the strengthening and maintenance of the midlevel vortex at the expense of low-level spinup. As argued by Tory et al. (2006), the divergence profile associated with stratiform precipitation (low-level divergence and midlevel convergence) would be detrimental to the spinup of the low-level circulation.

A south-north vertical cross section of $\theta_{e}$ constructed from dropwindsonde data (Fig. 16) west of the midlevel circulation center during IOP-2 (and west of the cross section in Fig. 14) reveals lower values of $\theta_{e}$ near the surface in the dropwindsonde profiles deployed at 0338 , 0046, 0324, and 0231 UTC (Fig. 16). As indicated in Fig. 11, the WC-130J was passing through the southern region of MCS-G at the time of the 0046 UTC dropwindsonde. The SFMR rain rates (Fig. 17, blue line) corresponding to the time of the 0046 UTC dropwindsonde confirm the presence of precipitation, and MTSAT IR brightness temperature, which was interpolated spatially and temporally to the WC-130J flight track (Fig. 17, red line), reveals low cloud-top temperatures indicative of a convective environment. Therefore, these regions of low-level low- $\theta_{e}$ air are interpreted as resulting from convective downdrafts. Above the near-surface cold pool in the 0046 UTC profile (Fig. 16), a plume of increased $\theta_{e}$ relative to the background environment extended into the upper levels, which is an indication of deep moist convection. By contrast, an extensive region of low- $\theta_{e}$ air in the midtroposphere north of the convective region (upshear) is also evident in Fig. 16, which was relatively cold, dry air associated with the TUTT cell to the north (near $24^{\circ} \mathrm{N}, 154^{\circ} \mathrm{E}$ in Fig. 4b).

\section{c. IOP-3 (2234 UTC 28 August-0510 UTC 29 August)}

At the time of IOP-3, the translation of the low-level circulation had increased significantly toward the northnorthwest (see Fig. 2a) and the wind structure was highly asymmetric due to the increasing low-level pressure gradient along the eastern side of the circulation (Fig. 5c). The third IOP was designed based on the broad cyclonically banded convective structure of MCS$\mathrm{H}$, which was almost entirely south of the circulation center in both the storm- and earth-relative frames (Fig. 18). This resulted in observations being southsoutheastward of the circulation center. Because the P-3 flight track was designed to circumnavigate the disturbance, the ELDORA radar coverage was limited to a narrow swath around the periphery of the disturbance, which did not allow for a detailed analysis of the convective structure or the winds near the circulation center to the north.

Despite these data coverage limitations, the SAMURAI analysis in the ground-relative frame (not shown) and 


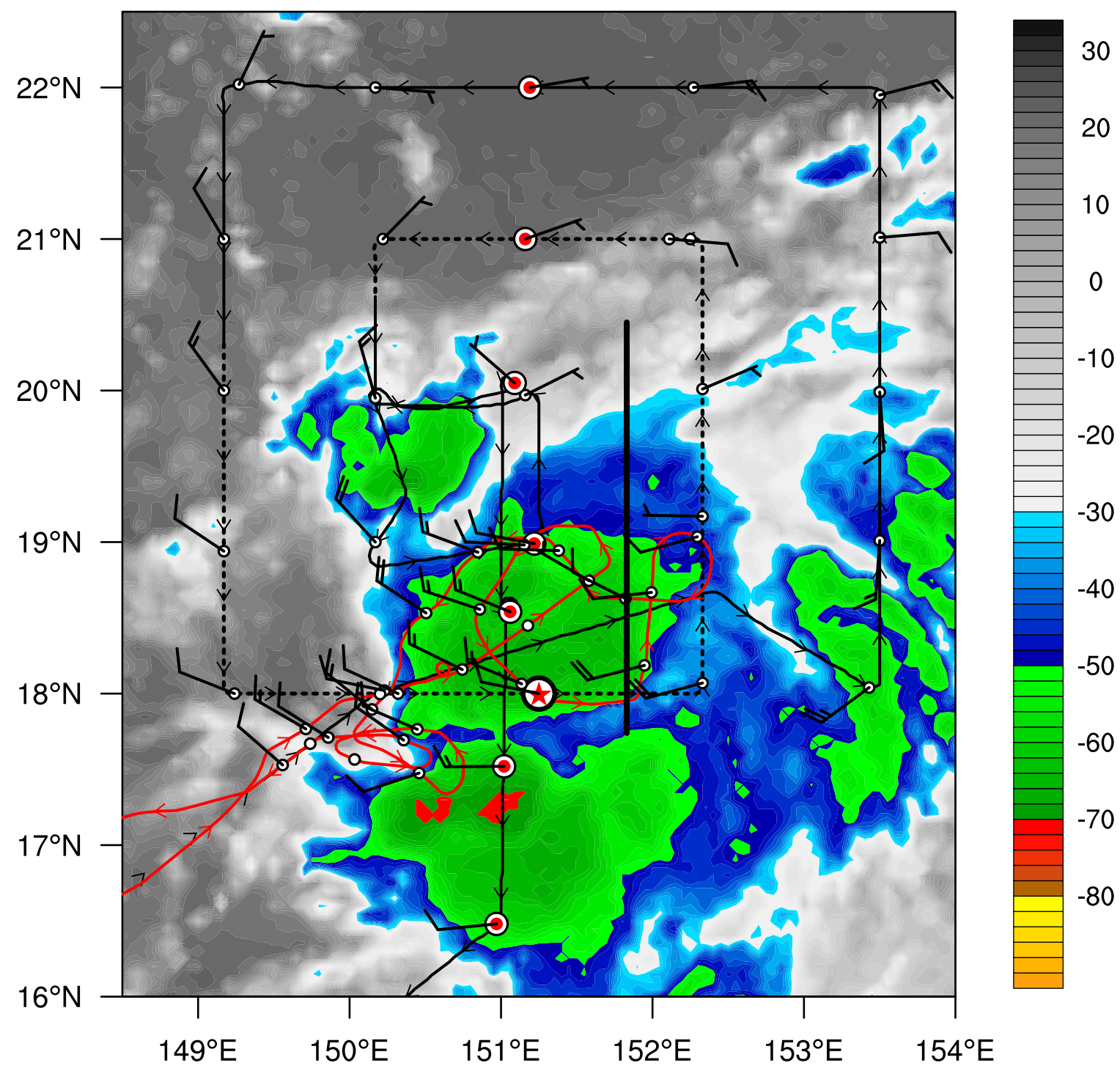

FIG. 11. MTSAT IR brightness temperature $\left({ }^{\circ} \mathrm{C}\right.$, shading) valid at 2345 UTC 27 Aug. The WC-130J flight track (black line), P-3 flight track (red line), and dropwindsonde deployment locations (white circles) are shown with wind barbs corresponding to $1500-\mathrm{m}$ height (1 full barb $=10 \mathrm{kt})$ for IOP-2 $(0225 \mathrm{~W}$ and $0325 \mathrm{~W})$. Red-filled dropwindsonde locations near $151^{\circ} \mathrm{E}$ were used in the vertical cross section in Fig. 16, and the red-filled star denotes the dropwindsonde deployed at 0046 UTC. The bold black line near $151.8^{\circ} \mathrm{E}$ denotes the location of the cross section in Fig. 14. The black dashed portion of the WC-130J flight track corresponds to the locations where SFMR rain rate and IR brightness temperature data were analyzed in Fig. 17.

the $1.5-\mathrm{km}$ dropwindsonde winds in Fig. 18a indicated strong southerlies along the east side of the low-level circulation with almost no northerly return flow on the western side of the circulation due to the rapid translation speed of the system. A diagnosis of the circulation structure from the storm-relative SAMURAI analysis (Fig. 18b) indicated that the low-level circulation on the northern periphery of the flight domain was elongated and shallow, as it only extended from the surface to $2-\mathrm{km}$ height. Furthermore, the midlevel circulation was displaced to the south (not shown), which was similar to the vertical structure observed during IOP-2.

\section{d. Thermodynamic evolution}

For each of the three WC-130J flights, MTSAT IR brightness temperatures were interpolated to the location and time of each dropwindsonde. Average vertical profiles of relative humidity, $\theta_{e}$, and DCAPE were created for each flight for all dropwindsondes with corresponding IR brightness temperatures less than $-35^{\circ} \mathrm{C}$ and for those with an IR brightness temperature greater 


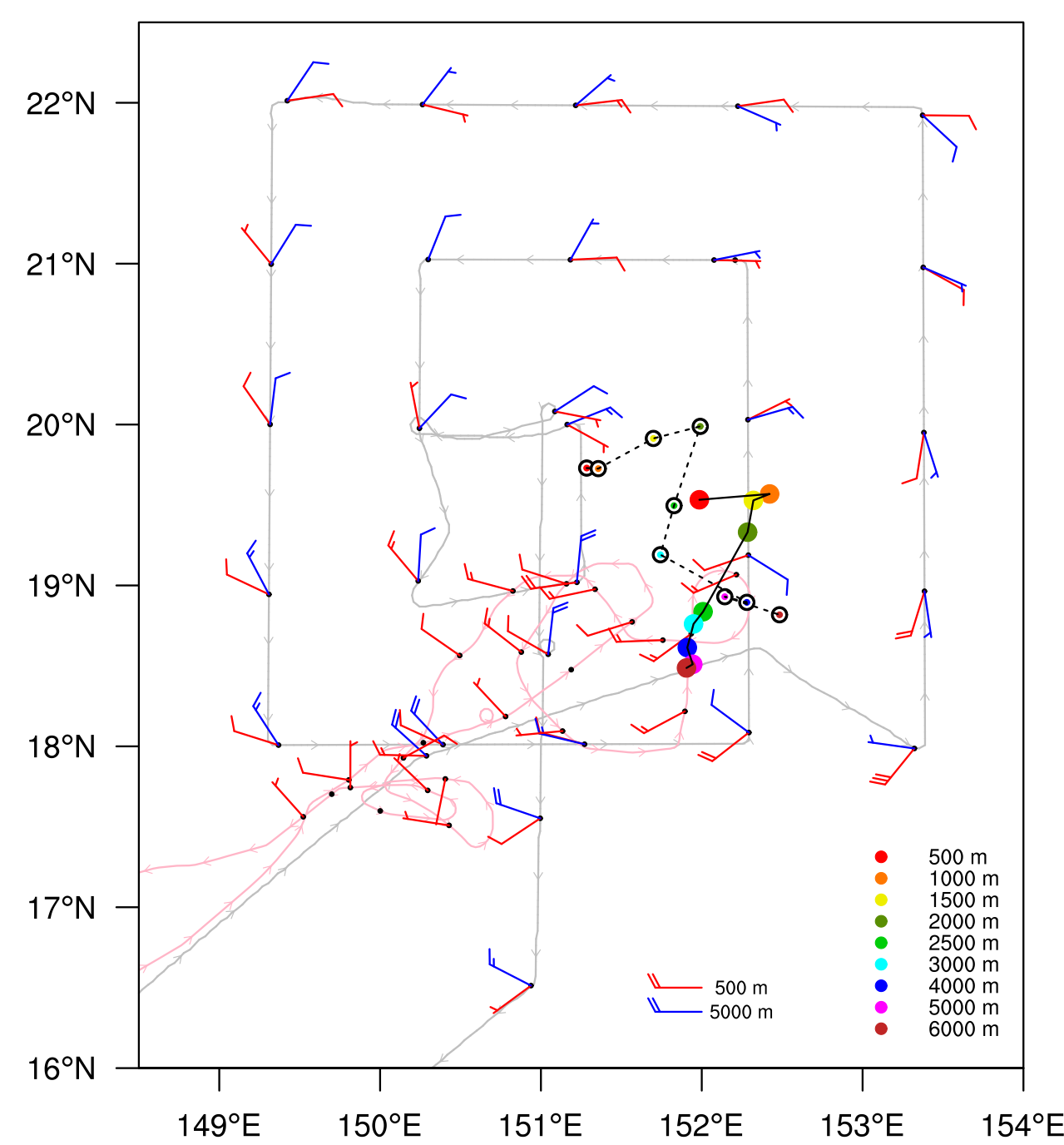

FIG. 12. Storm-relative WC-130J (0325W: 2103 UTC 27 Aug-0407 UTC 28 Aug) and P-3 (0225W: 0130 UTC 28 Aug-0520 UTC 28 Aug) flight tracks for IOP-2 in TCS025. Small black dots denote dropwindsonde locations and wind barbs correspond to heights shown in legend ( 1 full barb $=10 \mathrm{kt})$. Colored circles with black outlines connected with the dashed black line mark dropwindsonde-derived circulation center locations at heights listed in the inset. Solid colored circles connected by a solid black line mark the circulation center locations at heights listed in the inset obtained from the SAMURAI streamline analysis.

than $-35^{\circ} \mathrm{C}$, which allowed for a comparison of the thermodynamic conditions of the convective and nonconvective environments, respectively.

The average profiles reveal low-level relative humidity (Fig. 19a) was quite high $(>80 \%)$ throughout all IOPs in both the convective and nonconvective environments. However, mid- and upper-level relative humidity in the nonconvective environment decreased during IOP-2 (0325W) before increasing during IOP-3 $(0525 \mathrm{~W})$. Similar trends existed in the mid- and uppertropospheric $\theta_{e}$ (Fig. 19b). Low- $\theta_{e}$ air observed during IOP-2 resulted from the TUTT cell to the north being in close proximity to TCS025 (see Figs. 4b and 16). The largest values of DCAPE in the nonconvective environment also existed during IOP-2 (Fig. 19c). Therefore, a potential for strong downdrafts existed if dry environmental air associated with the TUTT mixed into the convective environment. By IOP-3, the TUTT cell had weakened considerably and had moved a significant distance away from TCS025 (see Fig. 5b), which lessened its thermodynamic impact on TCS025. In addition, the midlevel circulation (and region of higher- $\theta_{e}$ air) became increasingly elongated in the north-south direction leading up to IOP-3 (see Fig. 20f). Low- $\theta_{e}$ air 
(a)

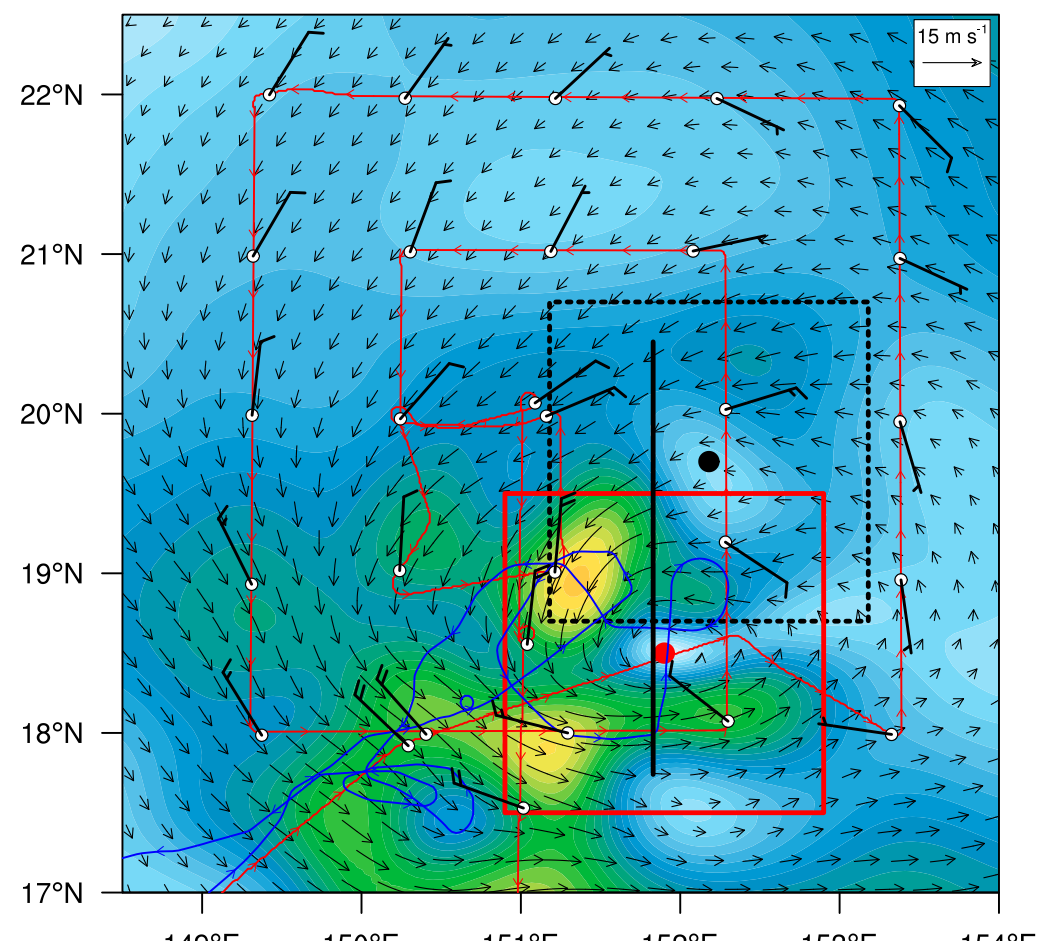

(b)

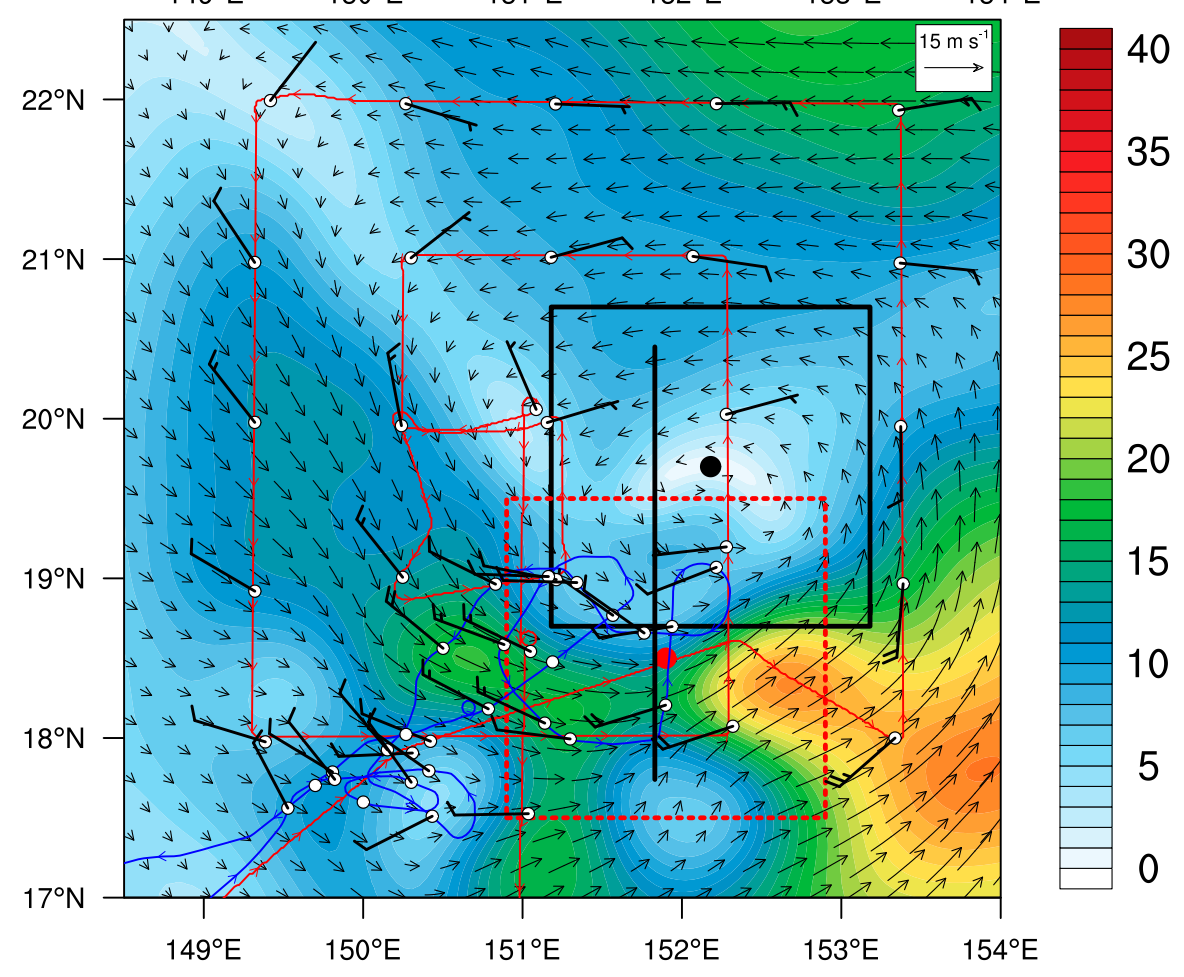

FIG. 13. Storm-relative wind speed (kt, shading) and vectors $\left(\mathrm{m} \mathrm{s}^{-1}\right)$ at (a) 5 and (b) $1.5 \mathrm{~km}$ from the 5 -km SAMURAI analysis valid at 0000 UTC 28 Aug. The WC-130J track for flight $0325 \mathrm{~W}$ is in red and the P-3 track for flight $0225 \mathrm{~W}$ is in blue. Black wind barbs ( 1 full barb $=10 \mathrm{kt}$ ) correspond to dropwindsonde winds corrected for storm motion. Solid black line denotes location of the cross section in Fig. 14. The $2^{\circ} \times 2^{\circ}$ black and red boxes are centered on the circulation center positions at 1.5 (black dot) and $5 \mathrm{~km}$ (red dot), respectively, and are used in the mesoscale vertical wind shear calculations in Fig. 7 and discussed in text. 
(a)

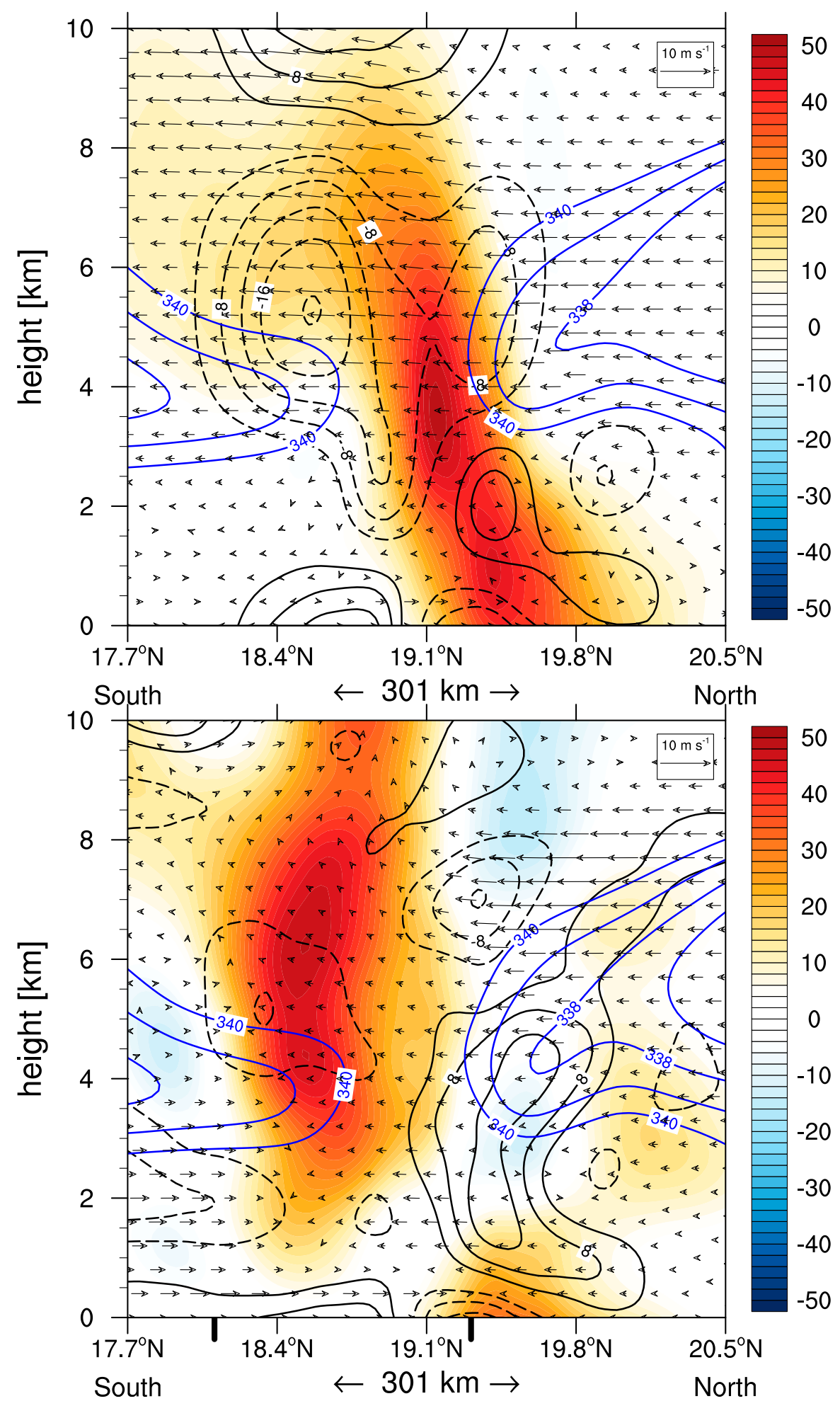

FIG. 14. South-north-oriented vertical cross section of relative vorticity $\left(10^{-5} \mathrm{~s}^{-1}\right.$, shading), divergence $\left(10^{-5} \mathrm{~s}^{-1}\right.$, black contours at $4.0 \times 10^{-5} \mathrm{~s}^{-1}$ intervals with negative values dashed), $\theta_{e}$ (K, blue contours for $\left.\theta_{e} \leq 340 \mathrm{~K}\right)$, and wind vectors in the plane of the cross section $\left(\mathrm{m} \mathrm{s}^{-1}\right)$ constructed from (a) the ECMWF background field and (b) the SAMURAI analysis with 5-km grid spacing valid at 0000 UTC 28 Aug. The location of the cross section corresponds to the solid black lines shown in Figs. 4,11, 13, and 15. The thick vertical black lines immediately below the abscissa in (b) correspond to the southern and northern extent of ELDORA Doppler radar at the longitude of the cross section (see Fig. 15). 


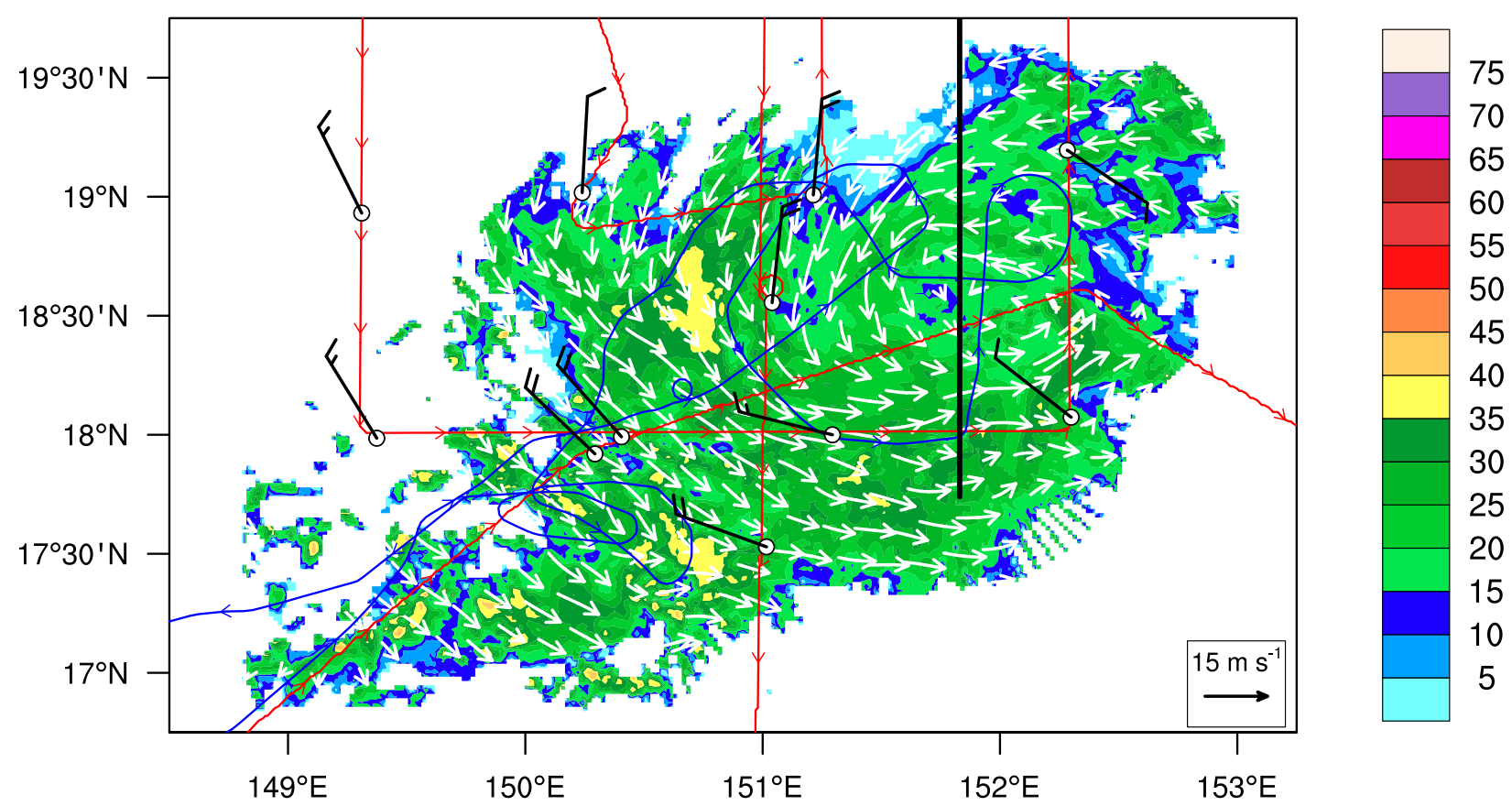

FIG. 15. ELDORA reflectivity (dBZ, shading) at 5-km height from the P-3 flight $0225 \mathrm{~W}$ early on 28 Aug. The white horizontal wind vectors $\left(\mathrm{m} \mathrm{s}^{-1}\right.$, with $15 \mathrm{~m} \mathrm{~s}^{-1}$ reference vector indicated at bottom right) correspond to the wind field at 5-km height derived using the SAMURAI analysis technique with $2-\mathrm{km}$ grid spacing. The WC-130J track for flight $0325 \mathrm{~W}$ is in red and the P-3 track for flight $0225 \mathrm{~W}$ is in blue. The black wind barbs correspond to dropwindsonde winds corrected for storm motion ( 1 full barb $=10 \mathrm{kt})$. The solid vertical black line denotes the location of the cross section in Fig. 14.

was still present to the west and southeast of the midlevel circulation, but the flight tracks of the WC-130J and $\mathrm{P}-3$ remained almost exclusively within this higher $-\theta_{e}$ air (not shown), which may partially account for the rebound in thermodynamic conditions observed during IOP-3.

Profiles of average temperature anomalies (Fig. 19d) from dropwindsondes deployed within $250 \mathrm{~km}$ of the circulation center reveal that the lower-tropospheric near-surface layer was $\sim 0.5 \mathrm{~K}$ colder relative to the dropwindsonde mean, and the middle and upper levels were generally warmer. During IOP-2 (missions $0225 \mathrm{~W}$ and $0325 \mathrm{~W}$ ), the inner-core environment was colder than during IOP-1 or IOP-3. Similar to the relative humidity, $\theta_{e}$, and DCAPE profiles, this is believed to have been due to the thermodynamic influence of the TUTT cell to the north.

The evolution of midlevel $\theta_{e}$ based on the ECMWF analysis prior to and extending past IOP-2 reveals low- $\theta_{e}$ air to the north of the broad midlevel circulation at 1200 UTC 27 August (Fig. 20a). The lowest $\theta_{e}$ air was near $23.5^{\circ} \mathrm{N}, 156^{\circ} \mathrm{E}$ and a trajectory analysis (not shown) reveals it was associated with the upper-level TUTT cell. By 0000 UTC 28 August (Fig. 20c), low- $\theta_{e}$ air had moved westward to become positioned north of the strengthening midlevel circulation. The low- $\theta_{e}$ air was being advected southward along the western side of the midlevel circulation (Figs. 20c-e). By 1200 UTC 28 August (Fig. 20e), low $-\theta_{e}$ air $(\sim 335 \mathrm{~K})$ had reached $18^{\circ} \mathrm{N}$ near $151^{\circ} \mathrm{E}$ while the lowest $\theta_{e}$ air associated with the TUTT cell continued to move farther to the northwest (Fig. 20f). Although the system-relative winds at $500 \mathrm{hPa}$ (Fig. 20) do not clearly indicate a direct pathway for low- $\theta_{e}$ air to enter the inner core of TCS025, the negative normalized Okubo-Weiss values in the low- and midlevels (Fig. 7b) indicates there was large horizontal shearing deformation surrounding the circulation, and suggests TCS025 lacked a quasi-closed circulation (see Tory et al. 2013). As a result, the circulation was more susceptible to the entrainment of low- $\theta_{e}$ air to the west of the circulation following 0600 UTC 28 August (Figs. 20d-f), and to the southeast of the circulation following 1200 UTC 28 August (Figs. 20e,f). The presence of low- $\theta_{e}$ air in the inner core is also suggested by the large negative lowlevel temperature anomalies observed from average dropwindsonde profiles of the inner-core environment during IOP-2 (Fig. 19d).

Near the end of IOP-2, deep convection associated with MCS-G was beginning to weaken, which is indicated by the broad areas of weak reflectivity in Fig. 15. This time corresponded to the waning stages of the diurnal convective cycle (see dashed lines in Fig. 9). 


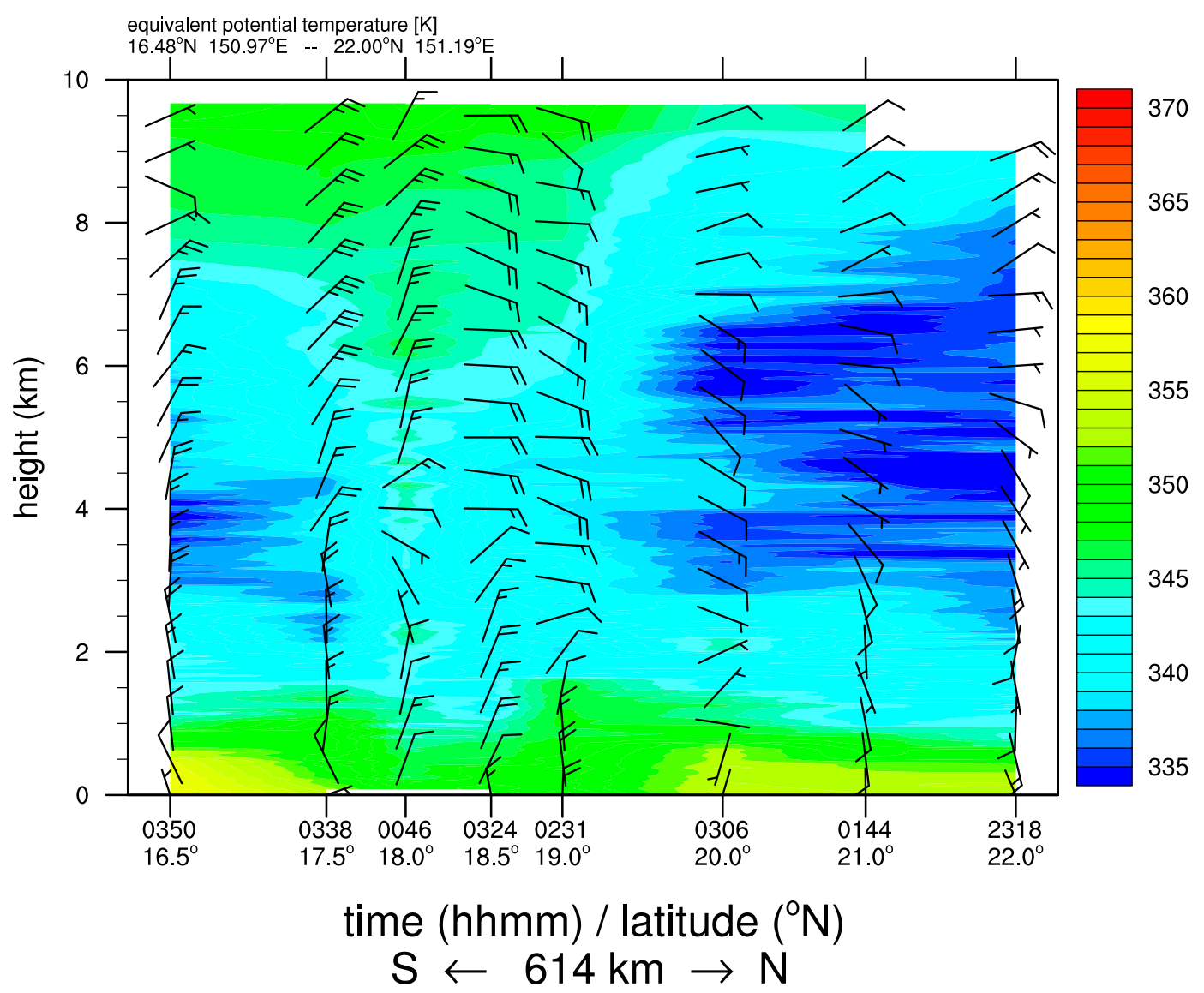

FIG. 16. South-north vertical cross section of $\theta_{e}(\mathrm{~K})$ constructed using dropwindsonde data (red-filled circles in Fig. 11) collected during the second WC-130J flight $(0325 \mathrm{~W})$. Wind barbs depict the dropwindsonde horizontal wind ( 1 full barb $=10 \mathrm{kt}$ ) and have been oriented to match the cross section such that wind barbs pointing from right to left correspond with northerly winds.

Although convection was present during the third IOP on 29 August, it appeared less organized than during the second IOP, and less intense based on average IR brightness temperatures (Fig. 9). In fact, there was a notable decline in convection after 0000 UTC 28 August in this region, and convection did not organize until the system had moved a considerable distance north (see Fig. 6a). This suggests that the low- $\theta_{e}$ air associated with the TUTT to the north of TCS025 led to a reduction in deep convection after this time.

\section{Discussion and conclusions}

The large-scale conditions conducive to tropical storm formation have been known for some time: high SST $\left(>26.5^{\circ} \mathrm{C}\right)$, abundant low- and midlevel moisture, convective instability, small vertical wind shear, and increased low-level relative vorticity (Gray 1975). In general, these conditions were present for TCS025; SSTs were greater than $29^{\circ} \mathrm{C}$ (not shown), and although the vertical wind shear magnitude was considerable at times $(\sim 15 \mathrm{kt})$, there were periods when it was much lower. Therefore, a careful examination of the mesoscale structure and interactions with the surrounding environment is necessary to explain possible reasons for the nondevelopment of TCS025.

Vertical misalignment of the circulation caused the low- to midtropospheric vertical wind shear (systemrelative flow) to be larger in magnitude relative to a well-aligned circulation. Based on IR brightness temperatures, convection was relatively weak for TCS025, especially considering that the coldest cloud tops are generally found in the western North Pacific (Liu et al. 2007). Deep convection that did form developed away from the circulation and tended to move southward (i.e., downshear) away from the low-level circulation. Given the appreciable misalignment of the circulation and the relatively weak and asymmetric tangential wind field, it appears that the convective activity associated with TCS025 was insufficient to promote vortex alignment as 


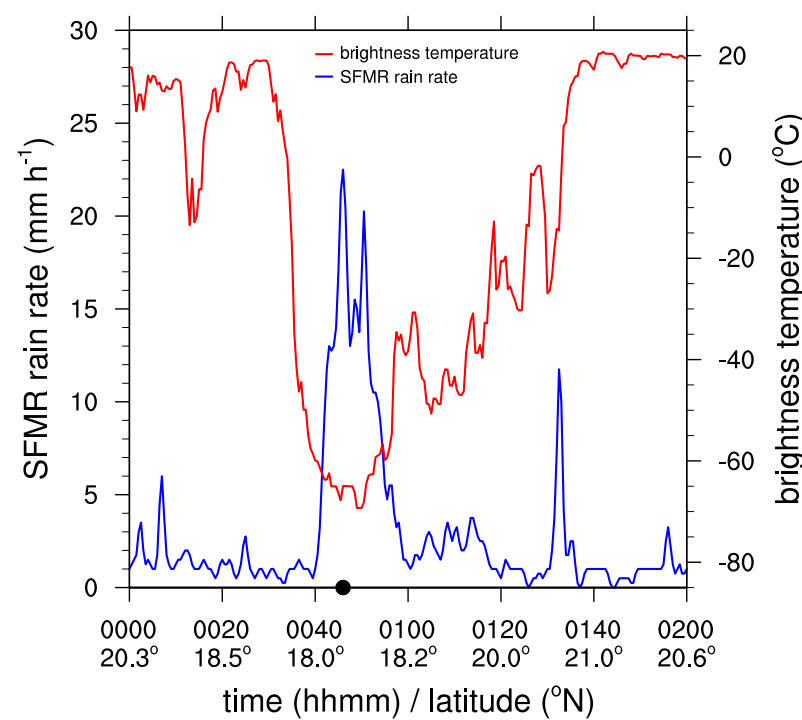

FIG. 17. SFMR rain rate $\left(\mathrm{mm} \mathrm{h}^{-1}\right.$, blue line and left ordinate) and MTSAT IR brightness temperatures $\left({ }^{\circ} \mathrm{C}\right.$, red line and right ordinate) interpolated spatially and temporally to the flight track during the second WC-130J flight $(0325 \mathrm{~W})$ from 0000 to 0200 UTC 28 Aug. Abscissa axis top labels correspond to UTC time. The black dashed line in Fig. 11 denotes the location along the flight track corresponding to this time interval. The black circle along the abscissa indicates the time of the 0046 UTC dropwindsonde in Fig. 16.

proposed by Davis and Ahijevych (2012), or further development while in the presence of negative environmental influences (i.e., vertical wind shear and low- $\theta_{e}$ air). Horizontal shearing deformation was also quite large in magnitude throughout the evolution of TCS025, and Raymond et al. (2011) concluded that it was an important factor in the nondevelopment of TCS025. This likely prevented further organization of convection and kept vorticity from consolidating. Large horizontal flow deformation in the low- and midtroposphere indicates a deep recirculation region was not present for TCS025 (Tory et al. 2013), which also increased the likelihood that low- $\theta_{e}$ air in the surrounding environment was entrained into the system.

The TCS025 environment did not follow the steady progression of drying in the midlevels typical of the nondeveloping system examined by Smith and Montgomery (2012) and Davis and Ahijevych (2012). There was essentially no difference in midlevel $\theta_{e}$ between IOP-1 and IOP-3, and low-level $\theta_{e}$ was actually highest during IOP-3, although sampling coverage may have been partly responsible for this. The large-scale environment of TCS025 was modulated by TUTT cells that moved westward to the north of TCS025. A trajectory analysis (not shown) indicates that the majority of the midlevel low- $\theta_{e}$ air to the north of TCS025 during IOP-2 originated from the TUTT cell that was originally to the east of TCS025. According to Komaromi (2013), the impact of midlevel low- $\theta_{e}$ air on storm development may be greater than low $-\theta_{e}$ air in the lower troposphere. Therefore, although vertical wind shear weakened when the TUTT cell was north of TCS025, the presence of low- $\theta_{e}$ air in the surrounding environment appears to have offset the positive impact of reduced vertical wind shear. The average midtropospheric $\theta_{e}$ in both the convective and nonconvective environments was lowest during IOP-2, and given the large horizontal shearing deformation, some entrainment was likely. This increased the negative impact potential of downdrafts (i.e., increased DCAPE). Consistent with this assumption, Park and Elsberry (2013) concluded that evaporative cooling and strong downdrafts counteracted low-level spinup for TCS025 based upon an examination of latent heating and cooling rates retrieved from ELDORA radar during IOP-3.

Molinari et al. (2013) hypothesized that repeated lulls in convective activity for Tropical Storm (TS) Edouard (2002) were a result of vertical wind shear-induced ventilation that caused low- $\theta_{e}$ air to be transported into the boundary layer via downdrafts. It is hypothesized that similar processes occurred for TCS025; strong downdrafts depleted boundary layer $\theta_{e}$ in precipitation regions, which subsequently reduced convective intensity. Alternatively, it is possible that dry air entrainment also weakened updraft intensity and limited the vorticity amplification process as proposed by Smith and Montgomery (2012). A convective lull occurred after MCS-G dissipated; deep convection was relatively absent at the convective maximum time late on 28 August, and the next episode of deep convection did not form until the system had moved a considerable distance to the north. Thus, when vertical wind shear was beginning to weaken on 28 August, thermodynamic conditions became less favorable such that the convective intensity diminished, and this limited further development.

Raymond et al. (2011) examined the nondevelopment of TCS025 along with several other developing and nondeveloping systems. They found positive low- and midlevel vorticity tendencies during IOP-2 and IOP-3, which are in basic agreement with similar calculations from the SAMURAI analyses in this study (not shown), and they concluded that TCS025 transitioned to a "bottom-heavy" mass flux profile by IOP-3. Despite these positive indicators and a broader environment considered generally favorable for formation, TCS025 failed to develop.

However, as Gjorgjievska and Raymond (2014) point out, a vorticity tendency analysis only provides a snapshot, and may not represent the longer-term evolution of a system. In fact, for several cases analyzed by 
(a)

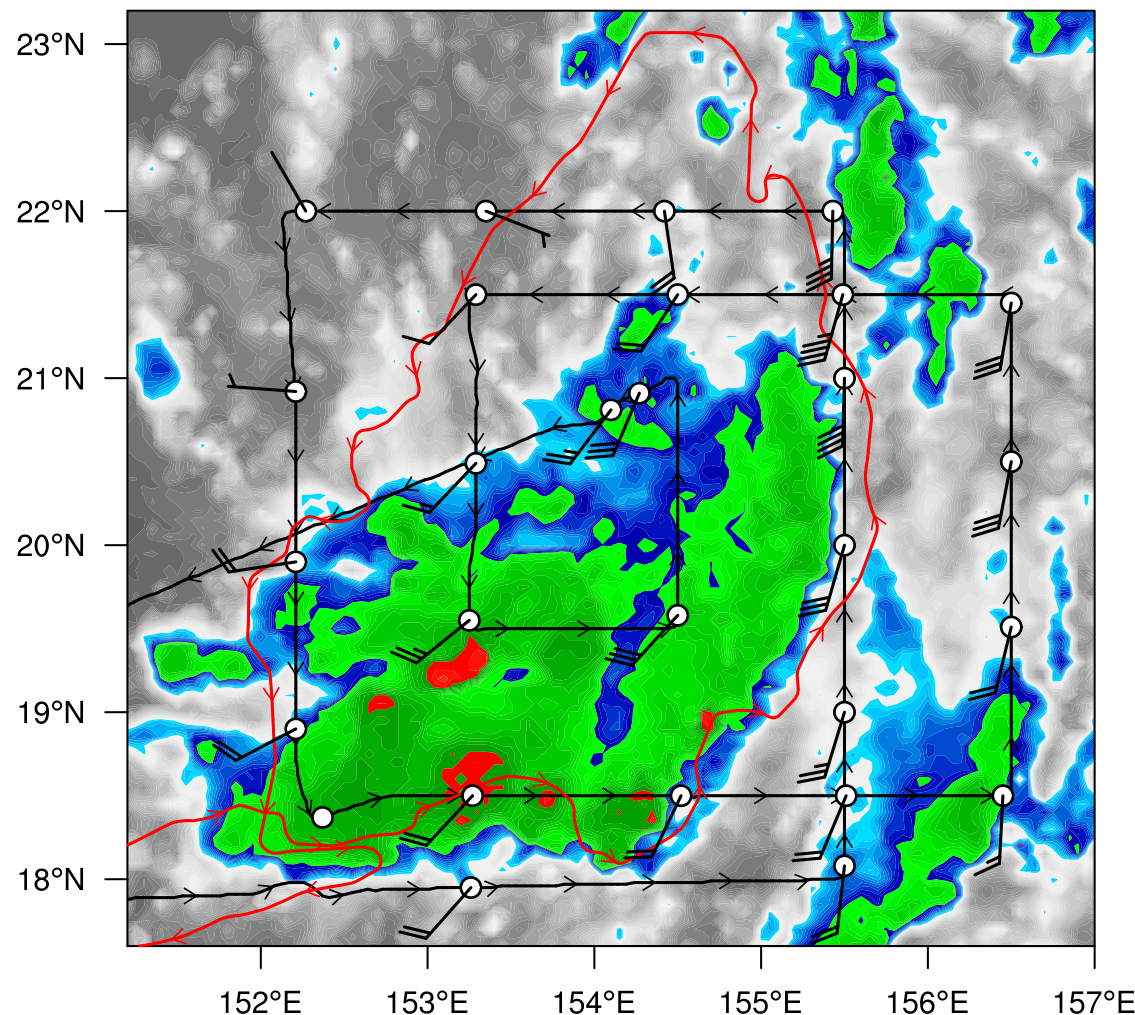

(b)

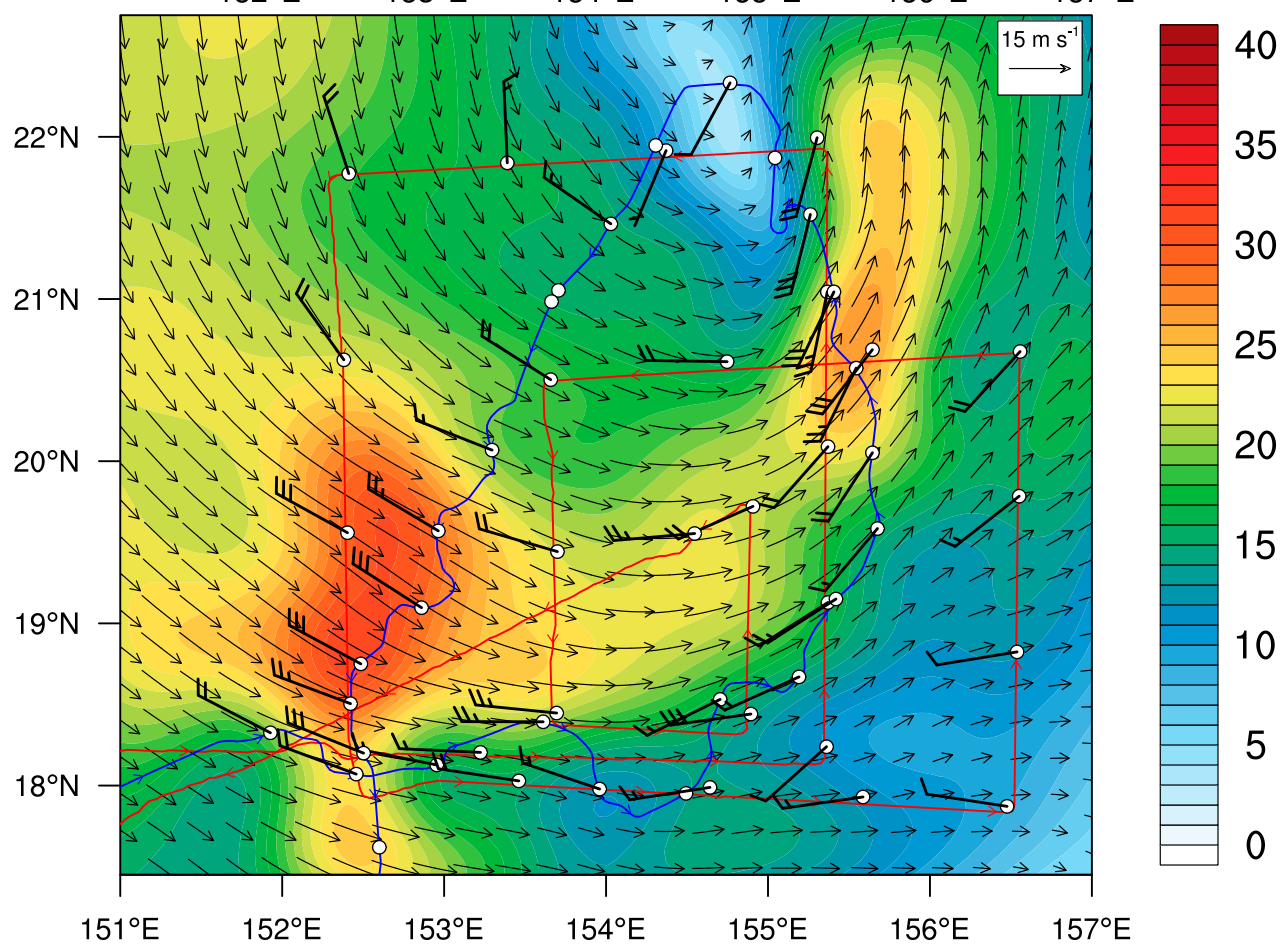

FIG. 18. MTSAT IR brightness temperature $\left({ }^{\circ} \mathrm{C}\right.$, shading) valid at 2345 UTC 28 Aug with flight tracks for the WC130J (black line) and P-3 (red line), dropwindsonde deployment locations (white circles), and horizontal dropwindsonde winds at $1.5-\mathrm{km}$ height ( 1 full barb $=10 \mathrm{kt}$ ) for IOP-3 $(0425 \mathrm{~W}$ and $0525 \mathrm{~W}$ ) in the ground-relative frame. (b) As in (a), but for storm-relative wind speed ( $\mathrm{kt}$, shading) and vectors $\left(\mathrm{m} \mathrm{s}^{-1}\right)$ at $1.5-\mathrm{km}$ height from the $5-\mathrm{km}$ SAMURAI analysis valid at 0000 UTC 29 Aug. Flight tracks, dropwindsonde deployment locations, and dropwindsonde winds have been adjusted for storm motion in (b). 
(a)

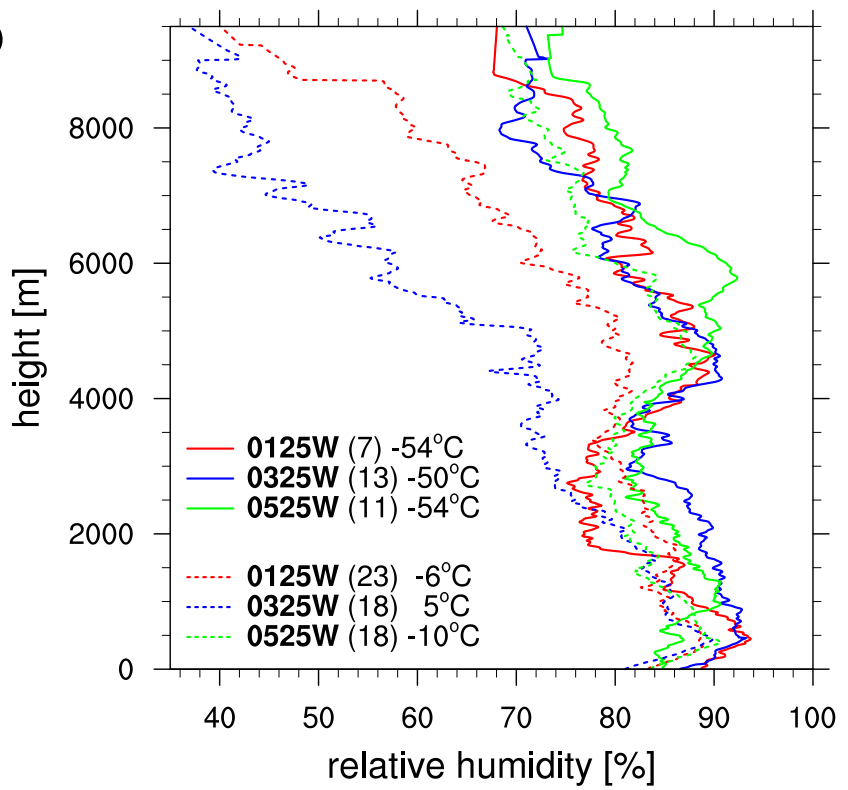

(c)

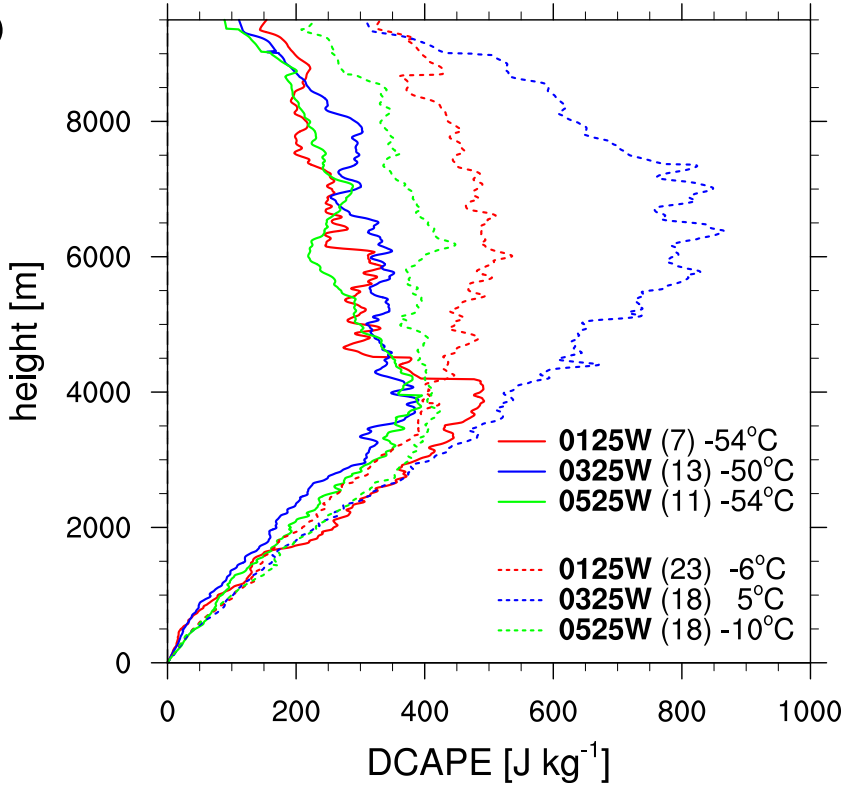

(b)

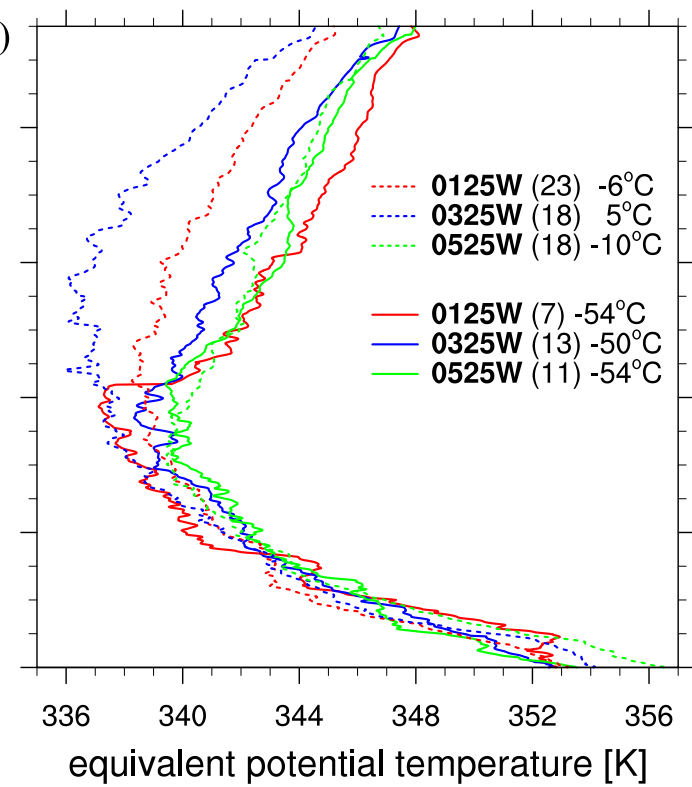

(d)

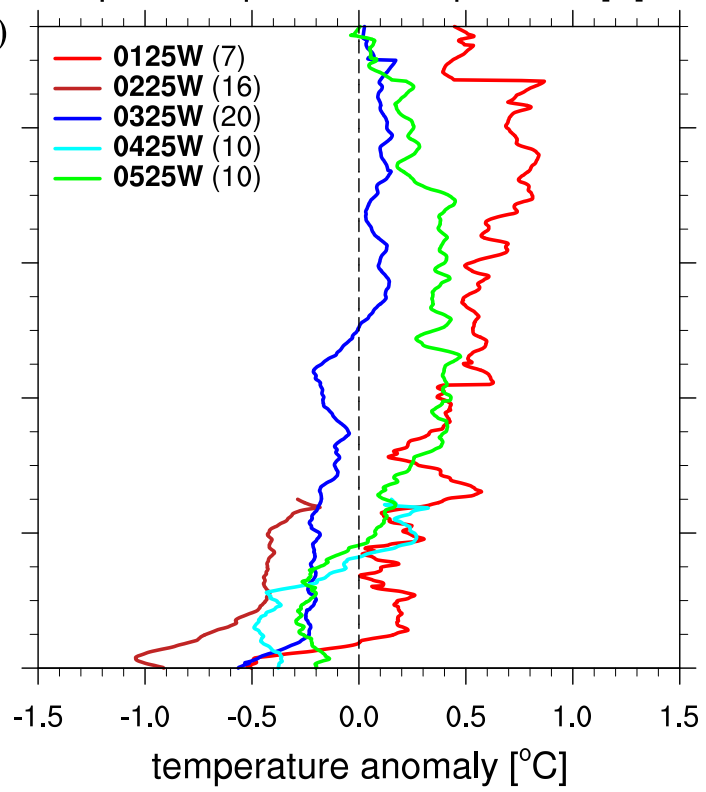

FIG. 19. Vertical profiles of (a) relative humidity (\%), (b) $\theta_{e}(\mathrm{~K})$, and (c) DCAPE $\left(\mathrm{J} \mathrm{kg}^{-1}\right)$ averaged for dropwindsondes for which the MTSAT IR brightness temperatures interpolated to the dropwindsonde time and location were $<-35^{\circ} \mathrm{C}$ (solid lines) and $>-35^{\circ} \mathrm{C}$ (dashed lines) during WC-130J aircraft missions shown in the inset. The average MTSAT IR brightness temperatures of dropwindsondes used to compute each average are shown in the inset. (d) Vertical profiles of temperature anomaly (K) from dropwindsondes averaged within $250 \mathrm{~km}$ of the analyzed ECMWF 850-hPa circulation center during aircraft missions shown in the inset. Each mean profile used to compute the average temperature anomaly was constructed from all dropwindsondes from each flight. The number of dropwindsondes used to compute each average is shown in the inset of each figure.

Raymond et al. (2011) and Gjorgjievska and Raymond (2014) that were observed over multiple days (including TCS025), the calculated vorticity tendency was opposite in sign to the observed trend. Gjorgjievska and Raymond (2014) also point out that a mass flux analysis may be even more sensitive to sampling biases since calculation of the average vertical velocity profile relies on shorter time scales and smaller horizontal scales of motion. For instance, our analysis of average dropwindsonde temperature anomaly profiles did not indicate a clear trend of increasing stabilization that might be expected based on the bottom-heavy mass flux profile found by Raymond et al. (2011) during IOP-3. Therefore, depending on the area sampled and the current phase of convection at the time of the observations (aircraft missions in TCS025 were generally conducted after the 

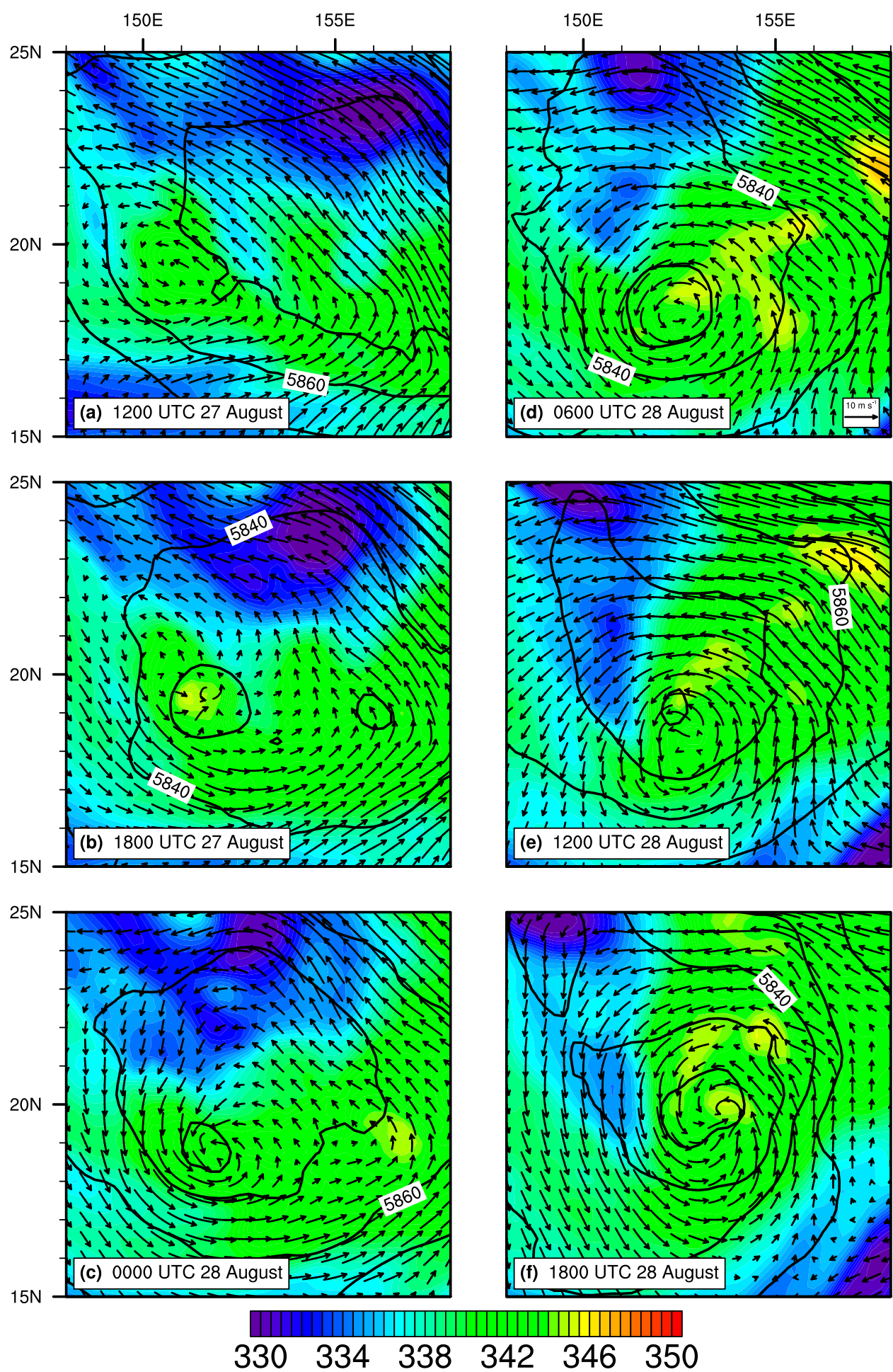

FIG. 20. (a)-(f) Equivalent potential temperature (K, shading), geopotential height (m, contours), and storm-relative wind vectors [ $\mathrm{m} \mathrm{s}^{-1}$, with $10 \mathrm{~m} \mathrm{~s}^{-1}$ reference vector indicated at bottom right in (d)] at $500 \mathrm{hPa}$ from the ECMWF analysis at times annotated in each panel. 
convective diurnal maximum time), a vorticity budget or mass flux analysis might represent a short-term fluctuation in intensity or not be representative of the system as a whole, which could lead to an incorrect assessment regarding the potential for storm formation.

The findings from this study suggest that convection associated with the TCS025 disturbance was not of sufficient intensity and was displaced too far from the circulation center to reduce the appreciable vortex misalignment of TCS025. The system-relative flow was larger due to the misalignment and large horizontal flow deformation suggests TCS025 lacked a quasi-closed recirculation region throughout its evolution. This likely allowed dry, cool, midlevel air originating from the TUTT cell to be entrained by convection near the circulation before being transported into the boundary layer through convective downdrafts, which acted to suppress subsequent convection. Had deep moist convection continued to occur near the midlevel circulation center, vortex realignment or the development of a new low-level circulation below the midlevel vortex (Davis and Ahijevych 2012) might have occurred. A coherent vertical vortex structure (i.e., a deep pouch) would have helped to limit the impacts of the midlevel low- $\theta_{e}$ air on 28 August, while at the same time providing a protective enclosure that would allow for a more efficient system-scale response to diabatic heating (Vigh and Schubert 2009) and development of a warm core.

Acknowledgments. This research was funded by National Science Foundation Grant ATM-0736003 and by the Office of Naval Research Marine Meteorology Grants N0001413WX20824 and N0001414WX20029. TCS-08 was sponsored by the Office of Naval Research Marine Meteorology Program and T-PARC was sponsored by an international consortium from the United States (National Science Foundation, Office of Naval Research, Naval Research Laboratory, and the U.S. Air Force), Germany (DLR, Forschungszentrum Karlsruhe), Japan (Japan Meteorological Agency), Korea (National Institute for Meteorological Research), and Canada (Environment Canada). The role of the National Center of Atmospheric Research/Earth Observing Laboratory (NCAR/EOL) during the field program and data management is acknowledged. MMB was supported by National Science Foundation Grant AGS0851077 and Office of Naval Research Marine Meteorology Grant N001408WR20129.

\section{REFERENCES}

Bartels, D. L., and R. A. Maddox, 1991: Midlevel cyclonic vortices generated by mesoscale convective systems. Mon. Wea. Rev., 119, 104-118, doi:10.1175/1520-0493(1991)119<0104: MCVGBM $>2.0 . C O ; 2$.
Bell, M. M., and M. T. Montgomery, 2010: Sheared deep vortical convection in pre-depression Hagupit during TCS08. Geophys. Res. Lett., 37, L06802, doi:10.1029/2009GL042313.

,$- \ldots$, and K. A. Emanuel, 2012: Air-sea enthalpy and momentum exchange at major hurricane wind speeds observed during CBLAST. J. Atmos. Sci., 69, 3197-3222, doi:10.1175/JAS-D-11-0276.1.

—, W.-C. Lee, C. A. Wolff, and H. Cai, 2013: A Solo-based automated quality control algorithm for airborne tail Doppler radar data. J. Appl. Meteor. Climatol., 52, 2509-2528, doi:10.1175/JAMC-D-12-0283.1.

Chen, S. S., and W. M. Frank, 1993: A numerical study of the genesis of extratropical convective mesovortices. Part I: Evolution and dynamics. J. Atmos. Sci., 50, 2401-2426, doi:10.1175/1520-0469(1993)050<2401:ANSOTG>2.0.CO;2.

Davis, C. A., and D. A. Ahijevych, 2012: Mesoscale structural evolution of three tropical weather systems observed during PREDICT. J. Atmos. Sci., 69, 1284-1305, doi:10.1175/ JAS-D-11-0225.1.

$\longrightarrow$, and - 2013: Thermodynamic environments of deep convection in Atlantic tropical disturbances. J. Atmos. Sci., 70, 1912-1928, doi:10.1175/JAS-D-12-0278.1.

_ C. Snyder, and A. C. Didlake, 2008: A vortex-based perspective of eastern Pacific tropical cyclone formation. Mon. Wea. Rev., 136, 2461-2477, doi:10.1175/2007MWR2317.1.

- S. C. Jones, D. Anwender, J. Badey, and L. Scheck, 2013: Mesoscale cyclogenesis over the western North Pacific Ocean during TPARC. Tellus, 65A, 18621, doi:10.3402/ tellusa.v65i0.18621.

Dunkerton, T. J., M. T. Montgomery, and Z. Wang, 2009: Tropical cyclogenesis in a tropical wave critical layer: Easterly waves. Atmos. Chem. Phys., 9, 5587-5646, doi:10.5194/acp-9-5587-2009.

Elsberry, R. L., and P. A. Harr, 2008: Tropical cyclone structure (TCS08) field experiement science basis, observational platforms, and strategy. Asia-Pac. J. Atmos. Sci., 44, 209-231.

Foerster, A. M., M. M. Bell, P. A. Harr, and S. C. Jones, 2014: Observations of the eyewall structure of Typhoon Sinlaku (2008) during the transformation stage of extratropical transition. Mon. Wea. Rev., 142, 3372-3392, doi:10.1175/ MWR-D-13-00313.1.

Frank, W. M., and E. A. Ritchie, 1999: Effects of environmental flow upon tropical cyclone structure. Mon. Wea. Rev., 127, 2044-2061, doi:10.1175/1520-0493(1999)127<2044:EOEFUT>2.0.CO;2.

Fu, B., M. S. Peng, T. Li, and D. E. Stevens, 2012: Developing versus nondeveloping disturbances for tropical cyclone formation. Part II: Western North Pacific. Mon. Wea. Rev., 140, 1067-1080, doi:10.1175/2011MWR3618.1.

Gjorgjievska, S., and D. J. Raymond, 2014: Interaction between dynamics and thermodynamics during tropical cyclogenesis. Atmos. Chem. Phys., 14, 3065-3082, doi:10.5194/acp-14-3065-2014.

Gray, W. M., 1975: Tropical cyclone genesis. Dept. of Atmospheric Sciences Paper 234, Colorado State University, Ft. Collins, CO, 121 pp.

- 1982: Tropical cyclone genesis and intensification. Topics in Atmospheric and Oceanographic Sciences: Intense Atmospheric Vortices, L. Bengtsson and J. Lighthill, Eds., Springer-Verlag, 3-20.

- 1998: The formation of tropical cyclones. Meteor. Atmos. Phys., 67, 37-69, doi:10.1007/BF01277501.

Hildebrand, P. H., and Coauthors, 1996: The ELDORA/ ASTRAIA airborne Doppler weather radar: High-resolution observations from TOGA COARE. Bull. Amer. Meteor. Soc., 77, 213-232, doi:10.1175/1520-0477(1996)077<0213: TEADWR $>2.0 . \mathrm{CO} ; 2$. 
Hock, T. F., and J. L. Franklin, 1999: The NCAR GPS dropwindsonde. Bull. Amer. Meteor. Soc., 80, 407-420, doi:10.1175/ 1520-0477(1999)080<0407:TNGD>2.0.CO;2.

Houze, R. A., Jr., 2004: Mesoscale convective systems. Rev. Geophys., 42, RG4003, doi:10.1029/2004RG000150.

Jones, S. C., 1995: The evolution of vortices in vertical shear. I: Initially barotropic vortices. Quart. J. Roy. Meteor. Soc., 121, 821-851, doi:10.1002/qj.49712152406.

Komaromi, W. A., 2013: An investigation of composite dropsonde profiles for developing and nondeveloping tropical waves during the 2010 PREDICT field campaign. J. Atmos. Sci., 70, 542-558, doi:10.1175/JAS-D-12-052.1.

Lee, C. S., 1989: Observational analysis of tropical cyclogenesis in the western North Pacific. Part I: Structural evolution of cloud clusters. J. Atmos. Sci., 46, 2580-2598, doi:10.1175/ 1520-0469(1989)046<2580:OAOTCI>2.0.CO;2.

Lee, W. C., M. Bell, C. Wolff, E. Loew, and M. Donovan, 2009: THORPEX Pacific Asian Regional Campaign (TPARC) and Tropical Cyclone Structure 2008 (TCS08) ELDORA data quality report. NCAR/Earth Observing Laboratory, 9 pp. [Available online at http://data.eol.ucar.edu/datafile/nph-get/ 110.084/ELDORA_TPARC_readme.pdf.]

Liu, C., E. J. Zipser, and S. W. Nesbitt, 2007: Global distribution of tropical deep convection: Different perspectives from TRMM infrared and radar data. J. Climate, 20, 489-503, doi:10.1175/ JCLI4023.1.

Lussier, L. L., III, M. T. Montgomery, and M. M. Bell, 2014: The genesis of Typhoon Nuri as observed during the Tropical Cyclone Structure 2008 (TCS08) field experiment-Part 3: Dynamics of low-level spin-up during the genesis. Atmos. Chem. Phys., 14, 8795-8812, doi:10.5194/acp-14-8795-2014.

McBride, J. L., 1981: Observational analysis of tropical cyclone formation. Part I: Basic description of data sets. J. Atmos. Sci., 38, 11171131, doi:10.1175/1520-0469(1981)038<1117:OAOTCF>2.0.CO;2.

_ - and R. Zehr, 1981: Observational analysis of tropical cyclone formation. Part II: Comparison of non-developing versus developing systems. J. Atmos. Sci., 38, 1132-1151, doi:10.1175/1520-0469(1981)038<1132:OAOTCF >2.0.CO;2.

Molinari, J., J. Frank, and D. Vollaro, 2013: Convective bursts, downdraft cooling, and boundary layer recovery in a sheared tropical storm. Mon. Wea. Rev., 141, 1048-1060, doi:10.1175/MWR-D-12-00135.1.

Montgomery, M. T., L. L. Lussier III, R. W. Moore, and Z. Wang, 2010: The genesis of Typhoon Nuri as observed during the tropical cyclone structure 2008 (TCS-08) field experimentPart 1: The role of the easterly wave critical layer. Atmos. Chem. Phys., 10, 9879-9900, doi:10.5194/acp-10-9879-2010.

_ , and Coauthors, 2012: The Pre-Depression Investigation of Cloud-Systems in the Tropics (PREDICT) experiment: Scientific basis, new analysis tools, and some first results. Bull. Amer. Meteor. Soc., 93, 153-172, doi:10.1175/BAMS-D-11-00046.1.

Park, M.-S., and R. L. Elsberry, 2013: Latent heating and cooling rates in developing and nondeveloping tropical disturbances during TCS-08: TRMM PR versus ELDORA retrievals. J. Atmos. Sci., 70, 15-35, doi:10.1175/JAS-D-12-083.1.

—, C.-H. Ho, J. Kim, and R. Elsberry, 2011: Diurnal circulations and their multi-scale interaction leading to rainfall over the South China Sea upstream of the Philippines during intraseasonal monsoon westerly wind bursts. Climate Dyn., 37, 1483-1499, doi:10.1007/s00382-010-0922-z.

Penny, A. B., 2013: Observations and high-resolution numerical simulations of a non-developing tropical disturbance in the western North Pacific. Ph.D. dissertation, Naval Postgraduate
School, Monterey, CA, 287 pp. [Available online at http://hdl. handle.net/10945/37691.]

Raymond, D. J., and H. Jiang, 1990: A theory for long-lived mesoscale convective systems. J. Atmos. Sci., 47, 3067-3077, doi:10.1175/1520-0469(1990)047<3067:ATFLLM>2.0.CO;2.

_ tropical cyclogenesis. Geophys. Res. Lett., 34, L06811, doi:10.1029/2006GL028607.

— veloping Typhoon Nuri (2008). Atmos. Chem. Phys., 11, 147163, doi:10.5194/acp-11-147-2011.

—, S. L. Sessions, and C. López Carrillo, 2011: Thermodynamics of tropical cyclogenesis in the northwest Pacific. J. Geophys. Res., 116, D18101, doi:10.1029/2011JD015624.

Simpson, J., E. Ritchie, G. J. Holland, J. Halverson, and S. Stewart, 1997: Mesoscale interactions in tropical cyclone genesis. Mon. Wea. Rev., 125, 2643-2661, doi:10.1175/1520-0493(1997)125<2643: MIITCG $>2.0 . C O ; 2$.

Smith, R. K., and M. T. Montgomery, 2012: Observations of the convective environment in developing and non-developing tropical disturbances. Quart. J. Roy. Meteor. Soc., 138, 17211739, doi:10.1002/qj.1910.

Testud, J., P. H. Hildebrand, and W.-C. Lee, 1995: A procedure to correct airborne Doppler radar data for navigation errors using the echo returned from the earth's surface. J. Atmos. Oceanic Technol., 12, 800-820, doi:10.1175/1520-0426(1995)012<0800: APTCAD $>2.0 . C O ; 2$.

Tory, K. J., M. T. Montgomery, and N. E. Davidson, 2006: Prediction and diagnosis of tropical cyclone formation in an NWP system. Part I: The critical role of vortex enhancement in deep convection. J. Atmos. Sci., 63, 3077-3090, doi:10.1175/JAS3764.1.

_ R. A. Dare, N. E. Davidson, J. L. McBride, and S. S. Chand, 2013: The importance of low-deformation vorticity in tropical cyclone formation. Atmos. Chem. Phys., 13, 2115-2132, doi:10.5194/acp-13-2115-2013.

Uhlhorn, E. W., P. G. Black, J. L. Franklin, M. Goodberlet, J. Carswell, and A. S. Goldstein, 2007: Hurricane surface wind measurements from an operational stepped frequency microwave radiometer. Mon. Wea. Rev., 135, 3070-3085, doi:10.1175/MWR3454.1.

Vigh, J. L., and W. H. Schubert, 2009: Rapid development of the tropical cyclone warm core. J. Atmos. Sci., 66, 3335-3350, doi:10.1175/2009JAS3092.1.

Wakimoto, R. M., W.-C. Lee, H. B. Bluestein, C.-H. Liu, and P. H. Hildebrand, 1996: ELDORA observations during VORTEX 95. Bull. Amer. Meteor. Soc., 77, 1465-1481, doi:10.1175/ 1520-0477(1996)077<1465:EODV >2.0.CO;2.

Waliser, D. E., and Coauthors, 2012: The "year" of tropical convection (May 2008-April 2010): Climate variability and weather highlights. Bull. Amer. Meteor. Soc., 93, 1189-1218, doi:10.1175/2011BAMS3095.1.

Yang, S., and E. A. Smith, 2006: Mechanisms for diurnal variability of global tropical rainfall observed from TRMM. J. Climate, 19, 5190-5226, doi:10.1175/JCLI3883.1.

Young, K., J. Wang, and D. Lauritsen, 2009a: THORPEX Pacific Asian Regional Campaign (TPARC) 2008 quality controlled Air Force C-130 dropsonde data set. NCAR/Earth Observing Laboratory, 9 pp. [Available online at http://data.eol.ucar.edu/datafile/ nph-get/110.085/readme.TPARC2008-C130.dropsondes.doc.] ,- , and,$- 2009 \mathrm{~b}$ : THORPEX Asian Pacific Regional Campaign (TPARC) 2008 quality controlled NRL-P3 dropsonde data set. NCAR/Earth Observing Laboratory, 9 pp. [Available online at http://data.eol.ucar.edu/datafile/nph-get/ 110.078/readme.TPARC2008-P3.dropsondes.doc.] 